\title{
Gravel wash mud, a quarry waste material as supplementary cementitious material (SCM)
}

\author{
Vishojit Bahadur Thapa, Danièle Waldmann, Claude Simon
}

1 Vishojit Bahadur Thapa, Laboratory of Solid Structures, University of Luxembourg, L-1359 Luxembourg,

2 Luxembourg

3 Danièle Waldmann, Laboratory of Solid Structures, University of Luxembourg, L-1359 Luxembourg,

4 Luxembourg, Tel.: +352 466644 5279, E-mail: daniele.waldmann@uni.lu

5 Claude Simon, Cimalux S.A., L-4002 Esch-sur-Alzette, Luxembourg

6 Abstract - The suitability of gravel wash mud (GWM), a sludge waste from gravel quarrying, is 7 examined for its use as a partial Ordinary Portland cement (OPC) clinker substitute. The gravel wash 8 mud was dried, milled into a fine powder and calcined at $750^{\circ} \mathrm{C}, 850^{\circ} \mathrm{C}$ and $950^{\circ} \mathrm{C}$. In this study, various

9 characterisation methods including particle size distribution (PSD), X-ray fluorescence (XRF), X-ray 10 diffraction (XRD) and the simultaneous thermal analysis (STA) were applied on the calcined GWM 11 powders to determine the optimal calcination temperature. Over 200 specimens were prepared based on 12 different cement paste and mortar mixes to investigate the potential of calcined GWM powders as SCMs. 13 The pozzolanic activity of the GWM powders was verified by applying strength-based evaluation 14 methods, simultaneous thermal analysis and SEM on hardened samples. Very promising strength15 enhancing capacities were observed for samples containing GWM powders calcined at $850^{\circ} \mathrm{C}$ with a 16 OPC replacement level of $20 \mathrm{wt} . \%$.

17 Keywords - Gravel wash mud (GWM), Supplementary cementitious materials, Alternative clay materials, 18 Calcined clays, Pozzolanic activity.

\section{Introduction}

20 The inevitable $\mathrm{CO}_{2}$ emissions related to cement manufacturing processes and its subsequent 21 environmental impacts have received considerable critical attention worldwide and have become one of 22 the key incentives for the development of environmental friendly and sustainable construction materials 23 [1-3]. Furthermore, the growing demand for binders, mortars and concrete products opposed to the 
increasing scarcity of raw materials for cement clinker production has imperatively stimulated the research on new binder technologies to assure the current and future demands for products based on cementitious materials [4-7]. Current trends in cement research have led to a large multitude of studies that suggest the partial substitution of OPC by admixtures, known as supplementary cementitious materials (SCM). Recent investigations and existing projects validate an important reduction of OPC usage by incorporation of SCMs in cement mixes [8] and the improvements of the final products' properties in contrast to the detrimental deteriorations of conventional concrete of aesthetical, functional or structural nature $[9,10]$. The beneficial effects of partial substitution of OPC by various SCMs on the packing of concrete mixtures, early hydration, mechanical performances and long-term durability have been extensively examined and confirmed. These improvements of mixture properties and performances due to addition of SCMs in cement-based mixtures can be attributed to three effects, which can occur simultaneously as coexisting processes or at distinctive stages over time [11-13]:

A) The chemical reaction: hydration of cementitious materials and pozzolanic reaction by formation of additional hydration products supplementary to the hydrated clinker phases [14-19].

B) The physiochemical impact: the finer particle size distribution of the added SCMs is correlated to larger contact surface area of the small particles, which provides larger interfacial area for the hydration reactions by performing as nucleation sites $[20,21]$.

C) The physical effect: packing effect, respectively filler effect, leads to formation of a more effective and denser aggregate-cement paste matrix by filling the gaps between the cement particles themselves and between the cement particles and the aggregates [12,13,22-25].

Despite their high potentials and efficacy as partial OPC substitutes, the most commonly used SCMs like fly ash (FA) [26], silica fume (SF), ground granulated blast furnace slag (GGBS) and metakaolin (MK) are nowadays commercially available products and their prices have risen over the last decades due to growing demand. Thus, valuable and reliable research studies have been carried out on potential alternative SCMs and their performance as cement substitutes has been evaluated and studied mainly for local markets. The use of locally available resources as SCMs shows a considerable economical potential 
as short transport routes as well as very low to no competitive price variations can be expected.

51 Alternative SCMs comprise rice husk [27-29], industrially processed clays [30,31], calcined clay-brick wastes [32-35], volcanic tuffs [36,37], pumices [20], modified reservoir sludge [38-40], waste expanded

53 perlite [41] and more [42-46].

54 Investigations on alternative SCMs using processed naturally occurring raw clay mixes and waste clay 55 products have increased worldwide. This paper focuses on the potential of a quarry waste material, 56 namely gravel wash mud (GWM), as SCM for partial substitution of OPC in cement-based mixes by 57 presenting a variety of selected investigations including different material characterisation analyses and performance-based experimental tests. The main objective is to suggest an optimal OPC replacement level and to evaluate the mechanical performance of the novel cement-based products. Large series of mixtures were prepared, which consist of different cement paste and mortar mixes containing GWM 61 powders calcined at $750^{\circ} \mathrm{C}, 850^{\circ} \mathrm{C}$ and $950^{\circ} \mathrm{C}$.

62 The physical and chemical properties as well as the mineralogy of the GWM powders were evaluated 63 using laser diffraction granulometry, the BET method, the X-ray fluorescence analysis, the quantitative 64 X-ray diffraction analysis and the simultaneous thermal analysis (STA), which combines 65 thermogravimetric analysis (TGA) and differential scanning calorimetry (DSC). Furthermore, the

66 hardened specimens were analysed using compressive strength tests combined with performance-based 67 evaluation methods, thermal analysis and scanning electron microscopy. The outcome of this study will 68 enrich the investigations on waste materials as efficient alternative SCMs for OPC supplementation. 69 Finally, the double benefit for society and industries consists of revalorizing an industrial waste product 70 as SCM in cement mixes in an economically attractive and environmentally friendly way.

\section{$71 \quad 2 \quad$ Materials and experimental program}

\section{$72 \quad 2.1 \quad$ Materials}

73 The used Ordinary Portland cement (OPC) is a commercial CEM I 42.5 R cement (clinker content $\geq 95$ 74 wt.\% according to EN 197-1 [47]) from Cimalux S.A, Luxembourg and a commercially available CEN- 
standard sands was used for the OPC mortars, certified in accordance to EN 196-1 [48] with a

76 characteristic grain size distribution with particle sizes ranging between $80 \mu \mathrm{m}$ and $2 \mathrm{~mm}$.

The gravel wash mud (GWM) was collected from a sandstone quarry in Folschette, Luxembourg

operated by Carrières Feidt S.A. The raw mud was extracted from a settling pond and stored in sealed recipients. The water content of the sludge was $44 \mathrm{wt} . \%$ and $32 \mathrm{wt} . \%$, in case a flocculation reagent was applied. The reddish brown mud-like deposit has a very plastic consistency. From geological point of view, the rock strata of the quarry consists of deposits of red sandstone. The GWM was desiccated at $105^{\circ} \mathrm{C}$ in a laboratory oven for two days. The dried GWM chunks were fragmented and ground into a powder, henceforth referred to as uncalcined GWM (UGWM) powder. The UGWM powder undergoes a thermal treatment procedure (calcination) to improve the reactivity of the aluminosilicates by dehydration and thermal decomposition (dehydroxylation) into a high-energy, amorphous raw material (CGWM). The calcination proceeded as follows: the powders were heated from room temperature up to temperature inside the chamber furnace. GWM powders was set at $750^{\circ} \mathrm{C}, 850^{\circ} \mathrm{C}$ and $950^{\circ} \mathrm{C}$. The water/binder ratio was fixed to 0.4 . For the 
101 the mortars were prepared at an arbitrarily fixed replacement level of $15 \mathrm{wt} . \%$ and a binder/aggregate 102 (b/ag) ratio of 0.75.

103 The mixing procedure was kept constant for all the series of binder and mortar mixes, respectively. The 104 quantities of Portland cement and calcined GWM powder were shortly dry-mixed at a mixing speed of $105125 \mathrm{rpm}$. While keeping the same mixing speed, the water is gradually added and the compound is mixed 106 for 180 seconds, followed by a final mixing at $250 \mathrm{rpm}$ for 90 seconds. For the mortar mixes, the sand 107 aggregates were added after the binder compound was mixed for 180 seconds, followed by mixing at $108125 \mathrm{rpm}$ and $250 \mathrm{rpm}$ for another 90 seconds each. The specimens were cast in prismatic moulds $(40 \mathrm{x}$ $10940 \times 160 \mathrm{~mm}^{3}$ according to EN 196-1 [48]) and compacted for 7 seconds on a vibrating table. After 110 casting, the moulds were covered with plastic plates (5 mm thick) to prevent rapid loss of moisture and 111 after 24 hours, the specimens were demoulded, wrapped in cellophane foil and cured at ambient 112 temperature until 24 hours before the uniaxial compression tests according to [48].

\begin{tabular}{|c|c|c|c|c|c|c|}
\hline \multirow{2}{*}{ Mixture* } & \multicolumn{6}{|c|}{ Calcination temperature $\mathrm{CT}^{* *}=750^{\circ} \mathrm{C} / 850^{\circ} \mathrm{C} / 950^{\circ} \mathrm{C}$; curing time of 7,28 and 56 days } \\
\hline & $\begin{array}{l}\text { Substitution } \\
\text { degree }\end{array}$ & CGWM & $\mathrm{OPC}$ & CEN Sand & $\mathrm{w} / \mathrm{b}^{* * * *}$ & $\mathrm{~b} / \mathrm{ag} * * * *$ \\
\hline$[-]$ & [wt.\%] & {$[\mathrm{g}]$} & [g] & [g] & {$[-]$} & {$[-]$} \\
\hline CG_R & 0 & 0 & 425 & - & 0.40 & - \\
\hline CG_CT_5 & 5 & 21 & 404 & - & 0.40 & - \\
\hline CG_CT_10 & 10 & 43 & 383 & - & 0.40 & - \\
\hline CG_CT_15 & 15 & 64 & 361 & - & 0.40 & - \\
\hline CG_CT_20 & 20 & 85 & 340 & - & 0.40 & - \\
\hline CG_CT_25 & 25 & 106 & 319 & - & 0.40 & - \\
\hline CG_CT_30 & 30 & 128 & 298 & - & 0.40 & - \\
\hline CGS_R & 0 & 0 & 225 & 180 & 0.40 & 0.75 \\
\hline CGS_CT_15 & 15 & 64 & 180 & 180 & 0.40 & 0.75 \\
\hline Thre & cimens of each & ixture wer & ced for & time $(7,28$ & and/or 90 & \\
\hline e.g. & CT_5 series co & sts of mixt & 750 & _5 and $\mathrm{CG}_{-} \mathrm{C}$ & & \\
\hline$* * *$ & r/binder ratio, & der equal $t$ & nt only & and CGWM & & \\
\hline$* * * *$ & der/aggregate $\mathrm{r}$ & & & & & \\
\hline
\end{tabular}

Table 1: Mix proportions of studied series of mixes

$114 \quad 2.3 \quad$ Experimental methods

115 2.3.1 Characterisation techniques applied on the primary powders and the hardened products 116 The laser diffraction method was used to determine the particle size distribution of the UGWM, CGWM 
$117\left(750^{\circ} \mathrm{C}, 850^{\circ} \mathrm{C}\right.$ and $\left.950^{\circ} \mathrm{C}\right)$ and OPC powders. A modular particle size analyser (HELOS-RODOS-

118 VIBRI, Sympatec GmbH, Germany) was utilised to measure the powder samples by dry powder 119 dispersion using Fraunhofer diffraction theory [41] to compute the PSD from the diffraction patterns.

120 The characterisation of the specific surface area was performed on UGWM and OPC powders (two 121 samples each) using the BET nitrogen gas adsorption method [42] according to ISO 9277:2010 [43], an 122 extended method of the Langmuir monolayer molecular adsorption [44] to multiple molecular layers. 123 The chemical composition of the powder samples was determined by X-ray fluorescence method using 124 a wavelength dispersive X-ray fluorescence (WDXRF) spectrometer (S8 TIGER, Bruker AXS GmbH, 125 Germany). The test specimens were prepared by pelletisation of the samples in a ring using the pressed 126 powder technique.

127 The crystalline structure was investigated by quantitative X-ray diffraction analysis using a powder X128 ray diffractometer using $\mathrm{Cu}-\mathrm{K} \alpha$ radiation (D4 ENDEAVOR, Bruker AXS GmbH, Germany). The 129 crystalline phases present in the GWM powders were identified by their characteristic d-spacings and 130 intensities using the XRD software DIFFRAC.EVA (Bruker AXS GmbH, Germany). The X-ray 131 diffraction patterns were processed using the program TOPAS (Bruker Corporation) using the 132 fundamental parameter approach for line profile fitting [49] and the powder diffractograms were refined 133 by the Rietveld method [50] after the crystalline phases were described using appropriate structural data 134 from ICSD database.

135 Furthermore, the accurate and direct detection of non-crystalline matter in a powder sample is not 136 possible with X-ray powder diffraction analysis, as those phases do not generate characteristic reflections 137 peaks (X-ray amorphous). However, due to the likeliness of the presence of non-crystalline content 138 (amorphous phases) in the GWM powders, its amorphous quantity is computed using quartz at $35 \%$ as 139 an internal reference [64]. This procedure of quantitative phase analysis of amorphous content assumes 140 that the internal reference quartz homogenously distributed within all powder samples, a narrow particle 141 size distribution of all phases is ensured and a random orientation of the crystallites is assured to reduce 142 preferred orientation effects [51,64]. With the known amount of the internal reference $\mathrm{W}_{\text {ref }}$ and its 
143

amount from the quantitative analysis $\mathrm{W}_{\mathrm{q}}$, the percentage of the amorphous content, $\mathrm{W}_{\text {amorphous, }}$, can be calculated as followed, adjusted from [51, 64]:

$$
\mathrm{W}_{\text {amorphous }}=1-\frac{\mathrm{W}_{\text {ref }}}{\mathrm{W}_{\mathrm{q}}} \times 10^{2}[\%]
$$

Once the amorphous content is determined and with consideration of the known quantity of the internal reference, the sum of all phases is normalized to $100 \%$.

Simultaneous thermal analyses (STA), a combination of thermogravimetric analysis (TGA) and differential scanning calorimetry (DSC), were performed on the GWM powder and the hardened cementbased binder. The applied thermo-analytical technique consists of the monitoring of the heat flow change and mass change of a sample as a function of temperature resp. time. The temperature was increased gradually from ambient temperature to $1000^{\circ} \mathrm{C}$. The analysis of the STA curves permits the assessment of the nature of changes in the samples due to the increase of temperature and whether, the endothermic and exothermic effects occur with associated mass change corresponding to e.g. a melting effect or phase transition; or without mass change corresponding to e.g. degradation. The mineralogical analysis in combination with the STA data consists a great tool to determine the optimal calcination temperature and the phase shifts of the GWM powders and the hardened specimens.

\subsubsection{Compressive strength test, relative strength test and pozzolanicity of the hardened} binders

For each mixture, the compressive strength was measured on three specimens with same curing ages using a compression test plant (TONICOMP III, Toni Technik GmbH, Germany), conform to the standard DIN EN 196-1 [48], with additional displacement transducers. An indirect evaluation method of the pozzolanic activity, namely the strength activity index (SAI), is applied to measure physical properties of hardened test samples and to evaluate the magnitude of the pozzolanic activity [16,52-61]. In addition, a modified method is suggested for the determination of the level of pozzolanic reactivity of the calcined GWM powders. The proposed relative strength index (RSI) is based on the same principal as the strength activity index (SAI) using the ratio of the compressive strength of samples containing the 
168 test pozzolan to the performance of a reference/control mixture as indicator for pozzolanic reactivity.

169 However, the RSI method follows the hypothesis that if a tested material would not show any pozzolanic 170 activity, neither any positive packing contribution nor reactivity to the cement matrix, then the expected 171 loss in strength would be expected to be directly proportional to the substitution degree or higher. The 172 RSP evaluation method directly provides information about the relative strength loss or gain of the 173 pozzolanic material to a certain OPC substitution degree. The first step of the proposed evaluation 174 (Figure 1) is to calculate the real potential (RP) which represents the ratio between the compressive 175 strength of the specimens containing the test pozzolan and the control mixture. In case, the ratio is equal or above $100 \%$, a net gain in strength was achieved from the substitution of OPC by calcined GWM

177 powders. However, if RP value is below $100 \%$, the consideration of the relative strength index (RSI), 178 which is calculated by Eq. (1), provides an indication whether a relative strength gain, respectively loss 179 occurred:

$$
\mathrm{RSI}=\mathrm{RP}-(100 \%-\mathrm{S})
$$

181 where RSI is the relative strength index, RP is the real potential (\%), representing the ratio between the 182 compressive strength of the specimens containing the test pozzolan and the control mixture, and $S$ is the 183 substitution degree of OPC by the SCM (\%).

\subsubsection{Microstructural characterisation of the cured binders}

185 The microstructure of the hardened specimens was analysed using a high-resolution scanning electron microscope (LEO 440 REM, Carl Zeiss SMT AG, Germany). This SEM unit enabled high quality observations of structure surfaces down to $5 \mathrm{~nm}$ realised by detection of secondary backscattered electrons (BSEs) from a high-energy beam of primary electrons in a raster scan pattern. The preparation

189 of small fractions of hardened material was performed after compression strength tests by gold coating.

190 The images of the microstructure of selected samples were obtained by performing SEM on small 191 fractions of the compressed specimens. 

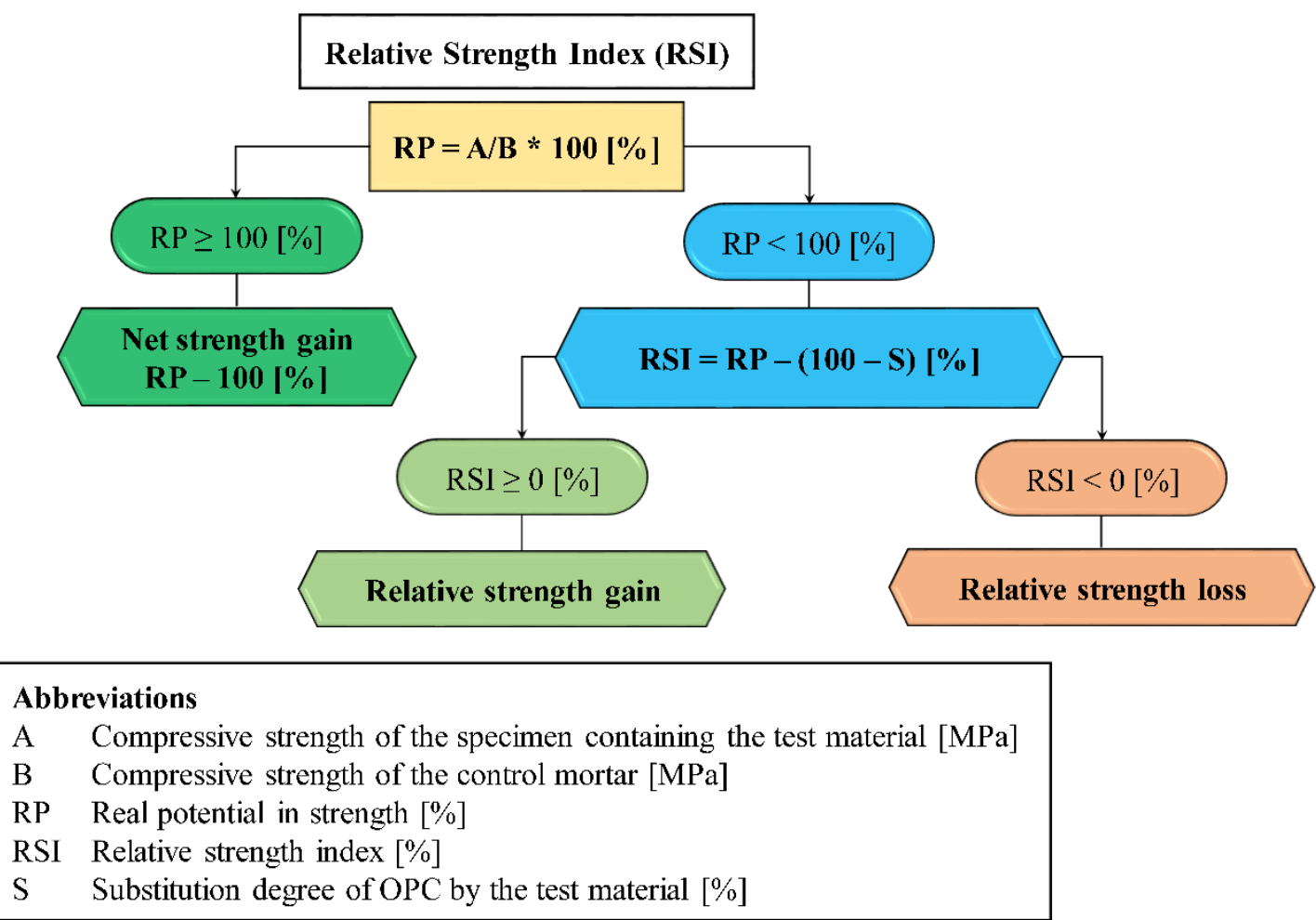

Figure 1: Relative strength index (RSI)

\section{Results and discussions}

1963.1 Characteristics of the raw materials

\subsubsection{Chemical analysis and PSD analysis}

198 Figure 2 displays the PSD curves of UGWM, CGWM and OPC. The PSD analysis shows that the GWM 199 powders present a very fine granulometry within a grain size range (d10-d90) from 1 to $35 \mu \mathrm{m}$ with a 200 mean particle size (d50) around 7-9 $\mu \mathrm{m}$ depending on the applied calcination temperature. CGWM 201 powders at $850^{\circ} \mathrm{C}$ and $950^{\circ} \mathrm{C}$ have a slightly coarser distribution than UGWM and CGWM at $750^{\circ} \mathrm{C}$ due 202 to the compaction of the minerals at high temperatures as a result of the sintering effect of clay particles $203[58,59]$. The OPC powder showed a specific surface area and a mean particle size of $436.50 \mathrm{~m}^{2} / \mathrm{kg}$ and $20411.58 \mu \mathrm{m}$, respectively. The aluminosilicate precursor UGWM showed a specific surface area of $205522.49 \mathrm{~m}^{2} / \mathrm{kg}$ with a mean particle size of $7.36 \mu \mathrm{m}$, whereas those for the CGWM powders, calcined at $206750^{\circ} \mathrm{C}, 850^{\circ} \mathrm{C}$ and $950^{\circ} \mathrm{C}$ were $524.99 \mathrm{~m}^{2} / \mathrm{kg}, 476.03 \mathrm{~m}^{2} / \mathrm{kg}, 426.50 \mathrm{~m}^{2} / \mathrm{kg}$ and $7.36 \mu \mathrm{m}, 8.61 \mu \mathrm{m}$, $2079.98 \mu \mathrm{m}$, respectively. The investigated CGWM powders show a finer grain size distribution than the 
208 investigated cement powder, which forecasts an enhanced packing density of the mixes, already at small

209 OPC substitution levels.

210 The chemical analysis (Table 2) confirms that the GWM is an aluminosilicate-rich material, which

211 presents an elemental composition with high silica $\left(\mathrm{SiO}_{2}\right)$, medium alumina $\left(\mathrm{Al}_{2} \mathrm{O}_{3}\right)$ and low iron oxide

$212\left(\mathrm{Fe}_{2} \mathrm{O}_{3}\right)$ contents.

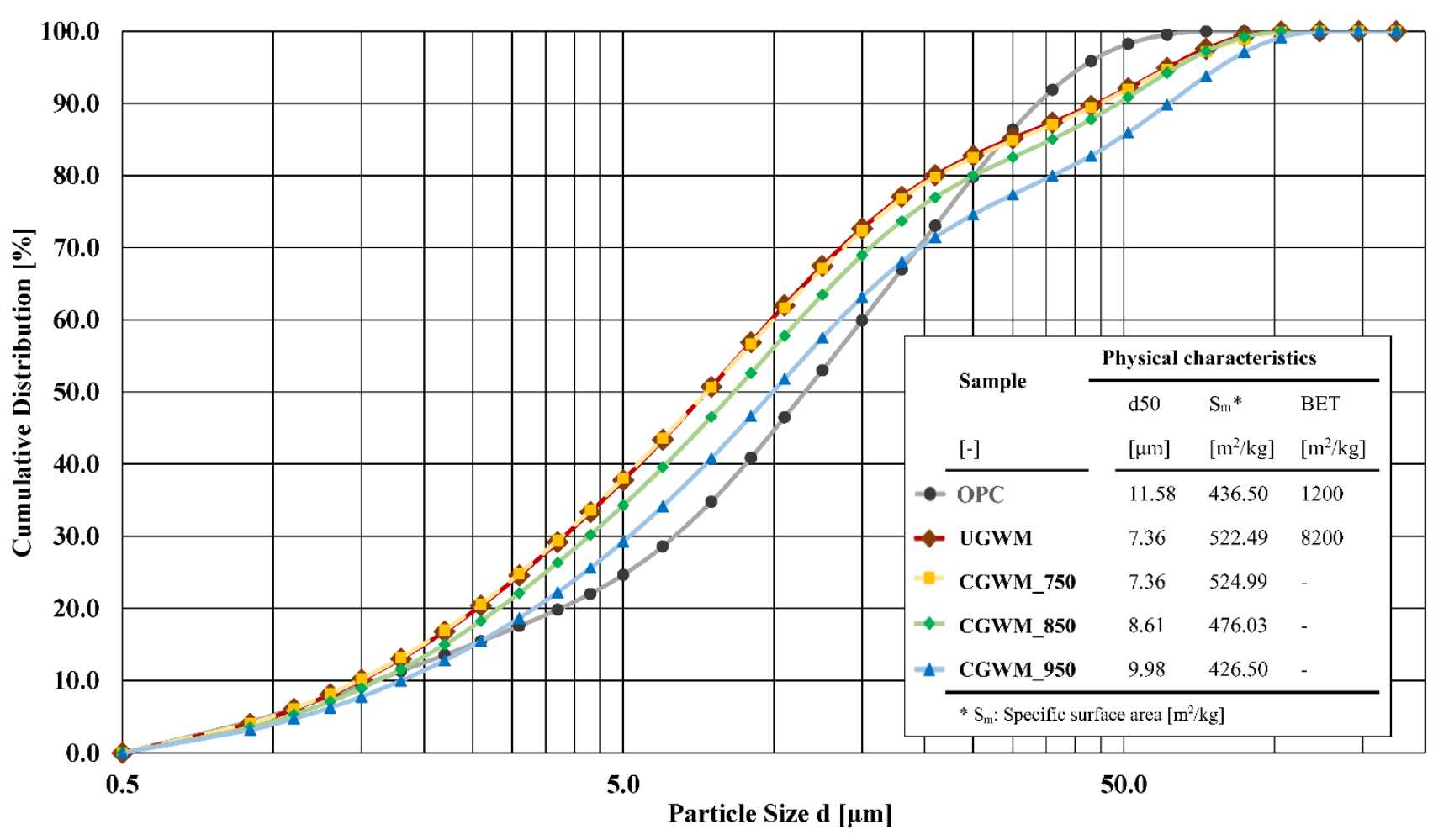

213

214 Figure 2: Particle size distribution and physiochemical characteristics of UGWM, CGWM (calcined at 215 $750^{\circ} \mathrm{C}, 850^{\circ} \mathrm{C}$ and $950^{\circ} \mathrm{C}$ ) and $\mathrm{OPC}$ powders

216

\begin{tabular}{lllllllllllll}
\hline \multirow{2}{*}{ Sample } & \multicolumn{1}{l}{ Chemical composition } & & & & & & & \\
\cline { 2 - 10 } & $\mathrm{SiO}_{2}$ & $\mathrm{Al}_{2} \mathrm{O}_{3}$ & $\mathrm{Fe}_{2} \mathrm{O}_{3}$ & $\mathrm{CaO}$ & $\mathrm{MgO}$ & $\mathrm{SO}_{3}$ & $\mathrm{Na}_{2} \mathrm{O}$ & $\mathrm{K}_{2} \mathrm{O}$ & $\mathrm{TiO}_{2}$ & $\mathrm{MnO}$ & $\mathrm{CeO}_{2}$ & $\mathrm{LOI}^{\prime}$ \\
\hline OPC & 17.10 & 4.23 & 3.84 & 59.20 & 1.10 & 2.91 & 0.19 & 0.47 & 0.30 & 0.31 & 0.15 & 2.4 \\
\hline UGWM & 52.30 & 15.70 & 7.53 & 0.33 & 1.34 & 0.07 & 0.19 & 2.19 & 0.69 & 0.05 & - & - \\
CGWM_750 & 52.71 & 17.26 & 8.51 & 0.22 & 1.14 & 0.07 & 0.23 & 3.08 & 0.75 & 0.08 & - & - \\
CGWM_850 & 53.70 & 17.00 & 7.47 & 0.34 & 1.52 & - & 0.20 & 2.73 & 0.75 & 0.07 & - & - \\
CGWM_950 & 53.93 & 17.45 & 7.87 & 0.22 & 1.34 & 0.04 & 0.25 & 3.11 & 0.63 & 0.08 & - & - \\
\hline
\end{tabular}

Table 2: Chemical composition of UGWM, CGWM and OPC powders 
219 Figure 3 illustrates the X-ray diffraction pattern of UGWM and the analysis reveals the presence of 220 amorphous material, quartz, muscovite, illite, kaolinite, hematite and $\mathrm{KAl}_{3} \mathrm{Si}_{3} \mathrm{O}_{11}$ in the GWM-based 221 powders [40]. The quantitative analysis (Table 3), which was carried out based on the method described 222 in [64], shows that the main crystalline phases identified were quartz, muscovite, followed by illite and 223 kaolinite as clay minerals, hematite and the amorphous portions. The increase of the calcination 224 temperature led to the transformation of the clay minerals into XRD amorphous phases. Two 225 dehydroxylation phases can be pointed out with kaolinite entirely transformed to metakaolinite at 226 temperatures below $750^{\circ} \mathrm{C}$, whereas illite shifts towards amorphous phases above $850^{\circ} \mathrm{C}$ [40]. In addition, 227 the quantity of muscovite is reduced above $750^{\circ} \mathrm{C}$ into a crystalline meta-phase, namely $\mathrm{KAl}_{3} \mathrm{Si}_{3} \mathrm{O}_{11}$.

228 Figure 4 shows the curves of the STA analysis of the GWM powder, the mass loss (TGA) and the heat 229 flow variation (DSC) of the GWM powder in function of the increase of temperature. The TGA curve 230 shows two main phases of mass reduction (total: - 4.38\%) of the investigated powder sample due to 231 gradual increase of the applied temperature from ambient temperature up to $1000^{\circ} \mathrm{C}$. The first gradual 232 mass loss $(-0.96 \%)$ can be perceived from $30^{\circ} \mathrm{C}$ to around $350^{\circ} \mathrm{C}$ due to the evaporation of interlayer 233 water of the aluminosilicate phases and the burning of organic matters or volatile components from the 234 samples. The greater mass reduction (-3.70\%) occurs from about $350^{\circ} \mathrm{C}$ up to about $900^{\circ} \mathrm{C}$ mainly driven 235 by the dehydroxylation of the clay minerals and further dehydration of structural water until a constant 236 mass state is reached. The DSC curve confirms the burnout of the organic matter at about $300^{\circ} \mathrm{C}$ and the 237 progressive dehydroxylation of the clay mineral phases from about $400^{\circ} \mathrm{C}$ to $550^{\circ} \mathrm{C}$, followed by the 238 phenomenon of quartz inversion (phase transition of quartz minerals) resulting in an endothermic peak 239 at $575.3^{\circ} \mathrm{C}[65,66]$. The findings of mineralogical analysis in combination with the STA suggest a 240 primary indication of the optimum range of calcination temperature for the GWM powder at above $750^{\circ} \mathrm{C}$ 241 as the loss in mass has more or less completed and the major phase shifts have occurred. 


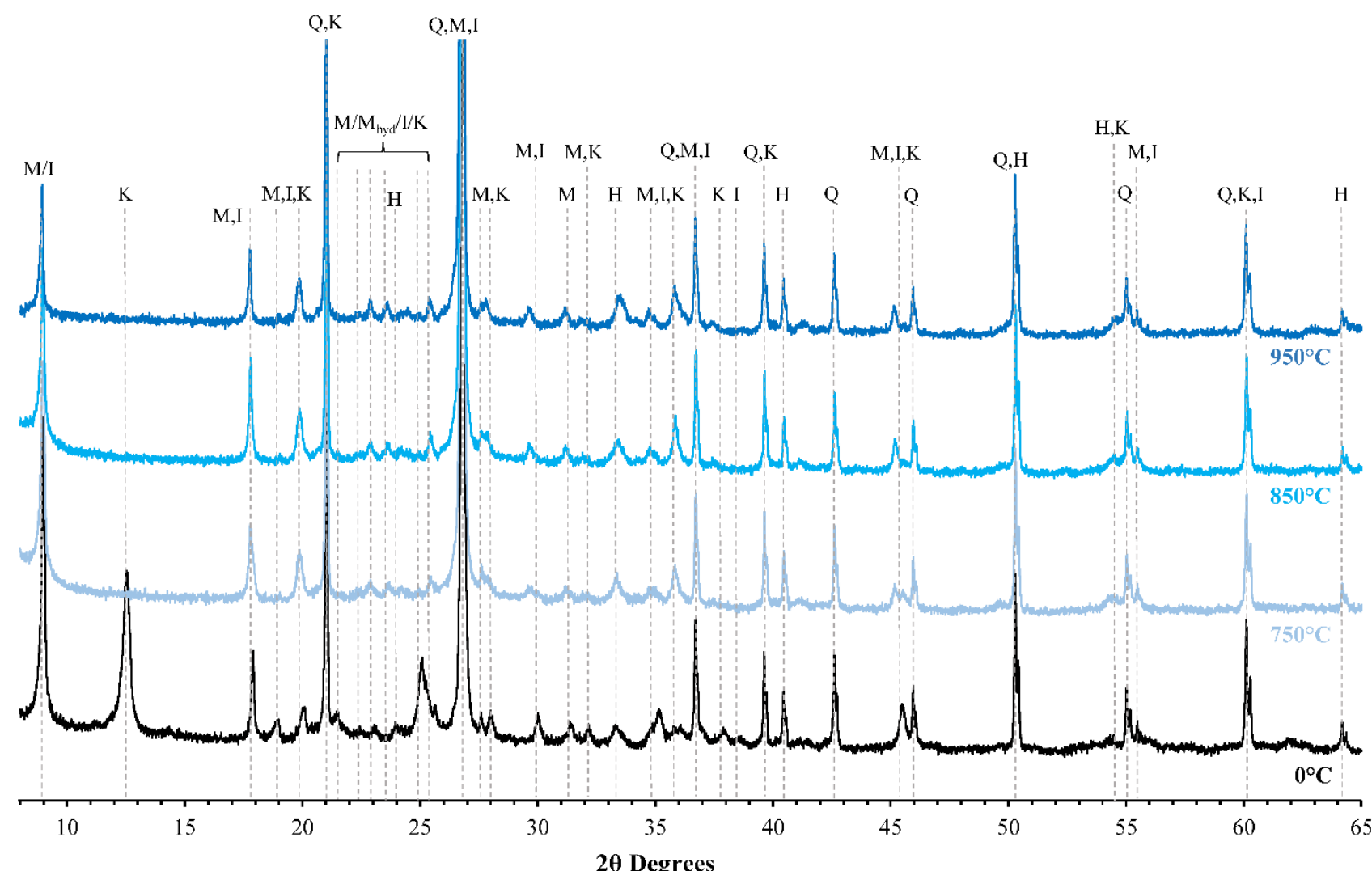

Figure 3: X-ray diffractogram of UGWM: Q - Quartz, M - Muscovite, I - Illite, K - Kaolinite, $\mathrm{H}$ - Hematite, $\mathrm{Mhyd}_{\text {hy }}-\mathrm{KAl}_{3} \mathrm{Si}_{3} \mathrm{O}_{11}$

\begin{tabular}{|c|c|c|c|c|c|c|c|c|}
\hline \multirow{2}{*}{ Sample } & \multicolumn{8}{|c|}{ Mineralogical composition [\%] } \\
\hline & $\mathrm{C}_{3} \mathrm{~S}$ & $\mathrm{C}_{2} \mathrm{~S}$ & $\mathrm{C}_{4} \mathrm{AF}$ & $\mathrm{C}_{3} \mathrm{~A}$ & Anhydrite & Calcite & Portlandite & Quartz \\
\hline \multirow[t]{2}{*}{ OPC } & 51.7 & 24.8 & 12.2 & 1.6 & 2.7 & 4.4 & 1.8 & 0.7 \\
\hline & Quartz* & Muscovite & Illite & Kaolinite & Hematite & $\mathrm{KAl}_{3} \mathrm{Si}_{3} \mathrm{O}_{11}$ & Amorph & \\
\hline UGWM & 35.0 & 16.5 & 13.2 & 11.3 & 0.6 & 1.5 & 21.9 & \\
\hline CGWM_750 & 35.0 & 9.3 & 13.8 & 0.4 & 2.0 & 8.3 & 31.1 & \\
\hline CGWM_850 & 35.0 & 8.7 & 12.4 & 0.3 & 2.1 & 7.2 & 34.4 & \\
\hline CGWM_950 & 35.0 & 3.6 & 8.9 & 0.5 & 2.5 & 6.6 & 42.9 & \\
\hline
\end{tabular}

* Quartz content fixed for normalisation of data 


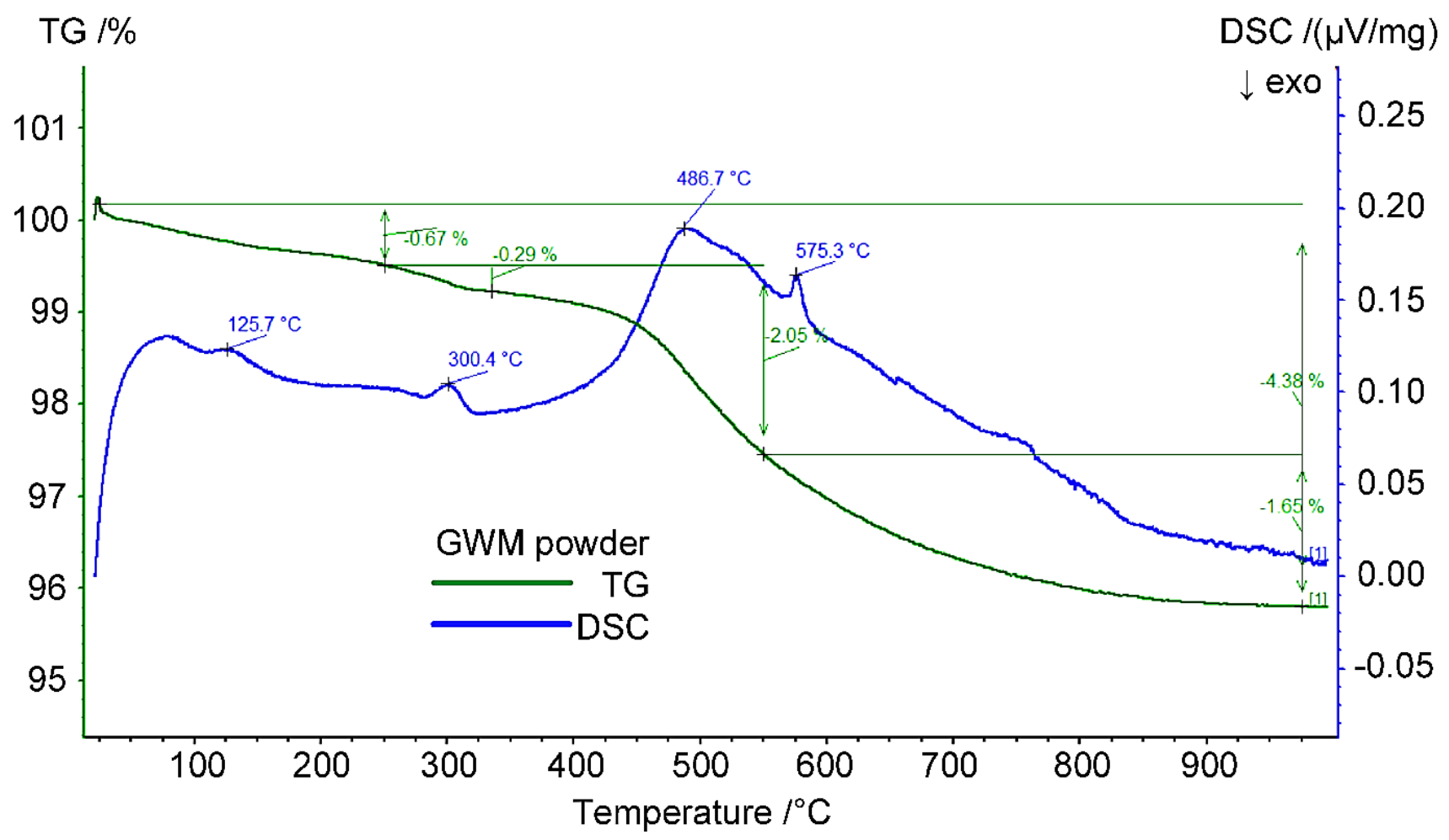

$248 \quad 3.2$ Characteristics of the hydrated specimens

$249 \quad 3.2 .1 \quad$ Compressive strength tests of hardened specimens and pozzolanic activity

250 Figure 5-7 show the evolution of the compressive strength of hardened cement pastes containing

251 different portions of GWM powders calcined at $750^{\circ} \mathrm{C}, 850^{\circ} \mathrm{C}$ and $950^{\circ} \mathrm{C}$ for up to 56 days of curing.

252 Each compressive strength value represents the mean compressive strengths out of three valid specimen

253 tests. All tested specimens showed a similar evolution of strength with a gain in compressive strength

254 with increasing curing days. The progress of hydration of the cement clinker phases led to the formation 255 of compact calcium silicate hydrates over the first days and months. With increasing curing ages, an 256 additional increase in strength is considered for specimens containing CGWM powders due to the 257 development of further reaction products from pozzolanic reaction. For example, an increase of 7.2 MPa 258 from 28 days to 56 days of curing was observed for CG_850_15 compared to an increase of 3.5 MPa for 259 the reference specimen over the same curing period. Moreover, an increase of the OPC replacement level 260 by the CGWM powders, regardless the calcination temperature, did not result in a proportional loss in 
261 strength of the hardened specimens after 28 resp. 56 days. Except at 7 days of curing, where a continuous

262 loss of performance is observable with increasing quantity of CGWM powder. This phenomenon at early 263 curing age can be related to the low reactivity of the CGWM powder and the fixed w/b ratio, which rather 264 builds a physical obstruction for the clinker hydration reactions in the cement matrix than an 265 enhancement due to pozzolanic reaction or better packing of the constituents. The development of the 266 compressive strength at higher curing ages at 28 days and 56 days does not indicate a clear decline in 267 compressive strength with increasing OPC substitution degrees. This suggests the formation of additional 268 hydration products due to reactions between the CGWM powders and OPC, which is a strong indication 269 for pozzolanic reaction. Furthermore, only the specimens containing GWM calcined at $750^{\circ} \mathrm{C}$ and $850^{\circ} \mathrm{C}$ 270 showed an increase in strength from OPC replacement level of 15 wt. $\%$ up to 25 wt. $\%$ after 56 days of 271 curing, whereas the development of compressive strength slightly declined for the specimens containing $272 \mathrm{GWM}$ powders calcined at $950^{\circ} \mathrm{C}$. The highest compressive strengths at 56 days of curing were achieved 273 for specimens CG_850_5, CG_950_5 and CG_850_10 with 53.97MPa, 53.07 MPa and 51.66 MPa 274 respectively.

275 Hardened mortar mixes (Figure 8) containing GWM powders calcined at $750^{\circ} \mathrm{C}, 850^{\circ} \mathrm{C}$ and $950^{\circ} \mathrm{C}$ at an 276 OPC replacement level of 15 wt.\% showed similar compressive strength development over the 277 investigated time period. The compressive strength of the hardened mortars CGS_850_15 exceeded the 278 strength of the reference mortar at 28 days and 56 days and CGS_950_15 surpassed the reference 279 compressive strength at 56 days. At early curing ages, the achieved compressive strength of the 280 investigated mortars were inferior to the performances of the reference mortar. However, higher 281 compressive strength values were realised at longer curing ages. The strength enhancement might be 282 related to the pozzolanic reaction in combination with the formation of a denser microstructure due to a 283 better cement paste distribution leading to an improved inter-aggregate bond compared to cement 284 matrices without aggregates. 


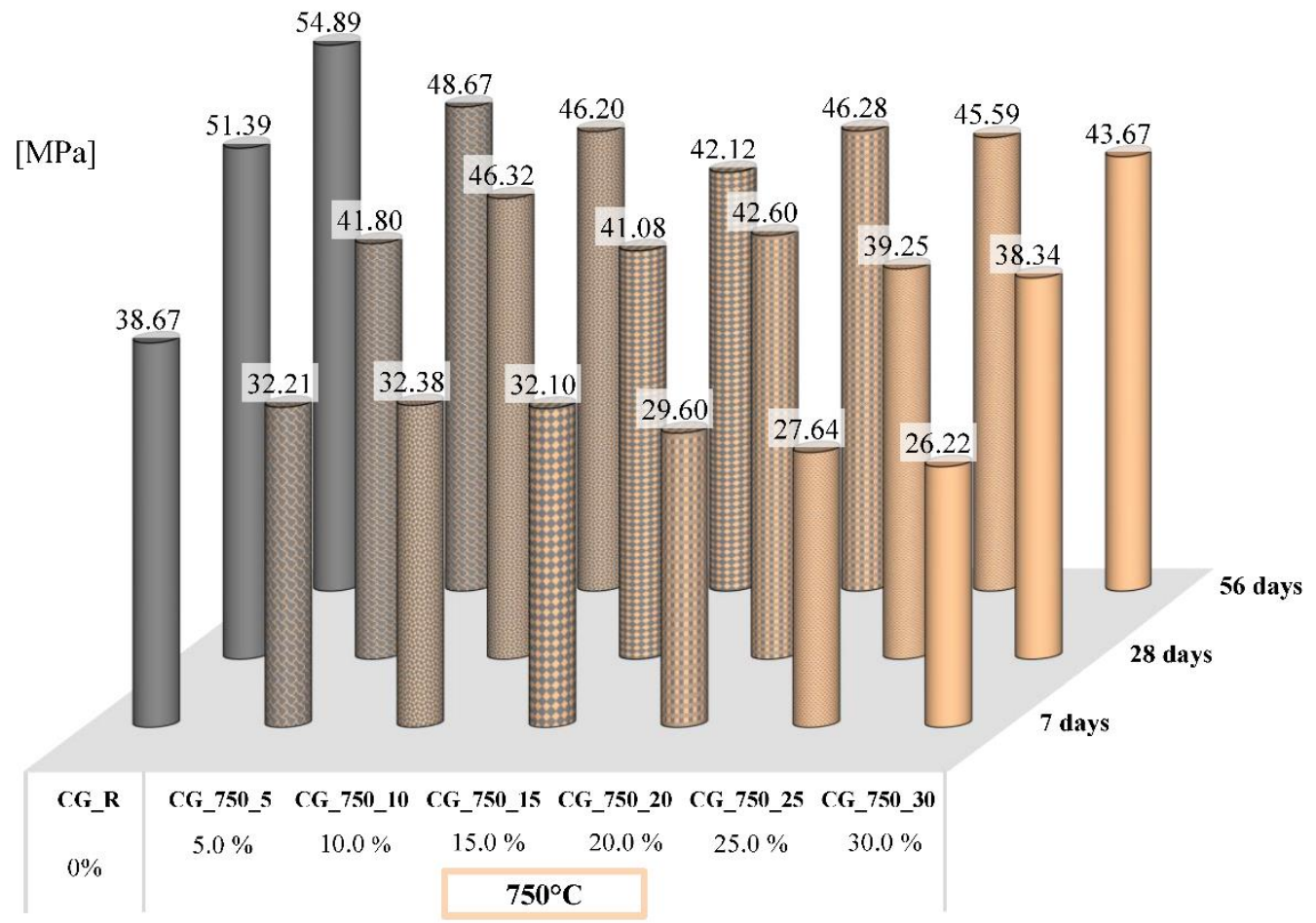

Figure 5: Development of the mechanical properties of hardened cement pastes containing CGWM 287 $\left(750^{\circ} \mathrm{C}\right)$ at different $\mathrm{OPC}$ substitution degrees

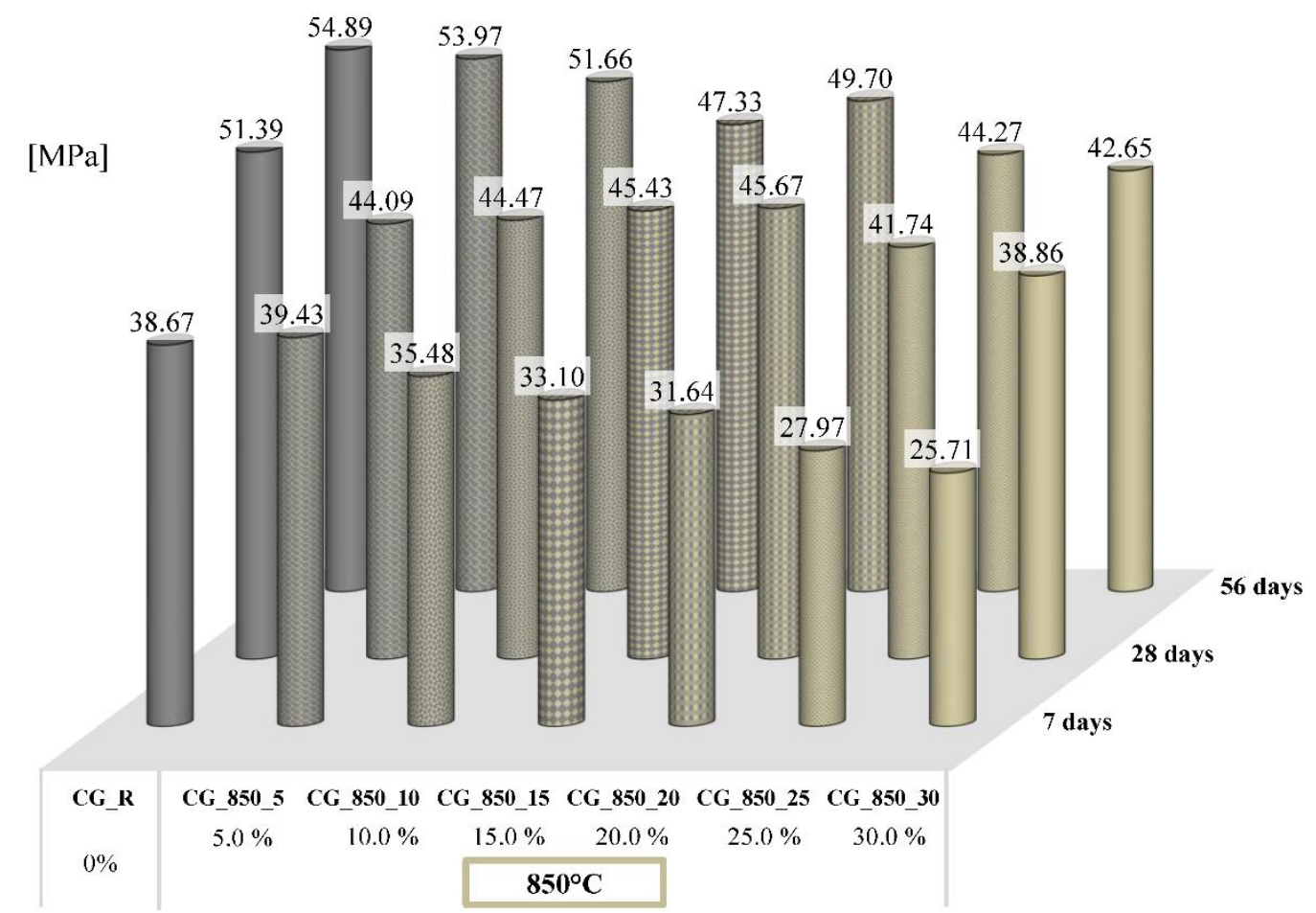

Figure 6: Development of the mechanical properties of hardened cement pastes containing CGWM $\left(850^{\circ} \mathrm{C}\right)$ at different OPC substitution degrees 


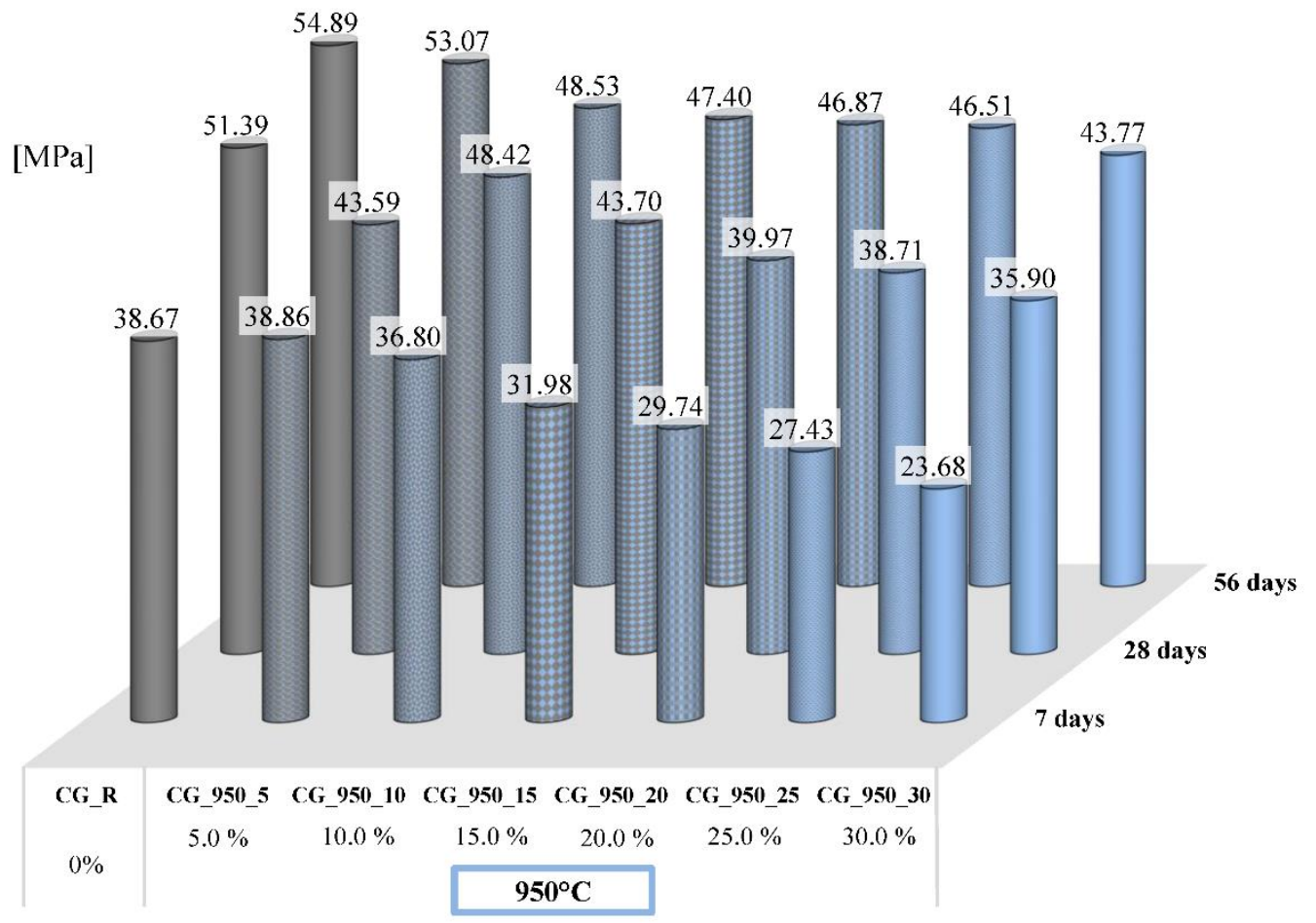

Figure 7: Development of the mechanical properties of hardened cement pastes containing CGWM $\left(950^{\circ} \mathrm{C}\right)$ at different $\mathrm{OPC}$ substitution degrees

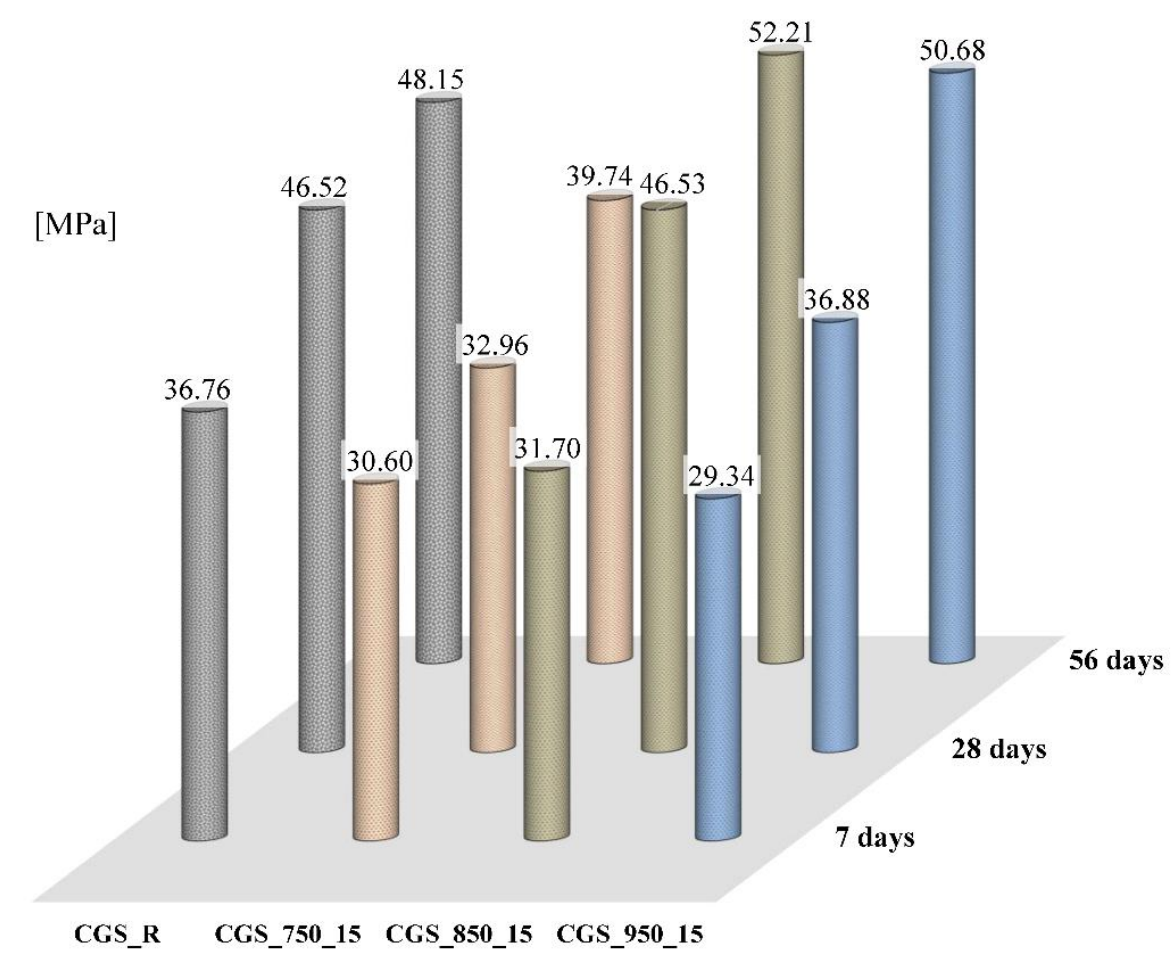

Figure 8: Development of the mechanical properties of hardened mortars containing different CGWM $\left(750^{\circ} \mathrm{C}, 850^{\circ} \mathrm{C}\right.$ and $\left.950^{\circ} \mathrm{C}\right)$ at fixed OPC substitution degree of 15 wt. $\%$

298 The direct comparison of absolute compressive strength is not sufficient to assess the pozzolanicity of 299 CGWM at different calcination temperatures as well as the potential of the OPC substitution. Therefore, 300 the strength activity index (SAI) method and the relative strength index (RSI) method are applied to 
301 determine the optimal calcination temperature and the efficient OPC substitution degrees.

302 The chemical composition of the CGWM powders fulfils the physiochemical requirements on calcined natural pozzolan according to specification in ASTM 618 [67] for usage as Portland cement admixtures.

304 The SAI were computed according to the test methods described in ASTM 311[68] for hardened cement 305 paste specimens containing $\mathrm{CGWM}$ powders $\left(750^{\circ} \mathrm{C}, 850^{\circ} \mathrm{C}\right.$ and $\left.950^{\circ} \mathrm{C}\right)$ at the specified $\mathrm{OPC}$ 306 replacement level of $20 \mathrm{wt} \%$ (Figure 9). The dashed line at 75\% represents the minimal SAI according 307 to [68] on physical requirement on calcined natural pozzolans after 7 or 28 days of curing age. This 308 assessment enables to evaluate if the test pozzolan reaches an acceptable level of strength development 309 in a cement-based mixture, irrespective of whether the enhancement is from cementitious and/or 310 pozzolanic nature.

311 The strength activity indices of the evaluated cement pastes were above the requirement limit of $75 \%$ at 312 all curing ages. The specimens containing GWM powders calcined at $850^{\circ} \mathrm{C}$ achieved the highest SAI of $31381.8 \%, 88.9 \%$ and $90.5 \%$ at 7, 28 and 56 days, respectively. The evaluation of the SAI confirms the 314 potential of the CGWM powders for strength developing properties as pozzolanic materials and indicates 315 that the optimal calcination temperature of the GWM powders is $850^{\circ} \mathrm{C}$. However, the OPC replacement 316 level of $20 \mathrm{wt} \%$ should be considered as a fixed evaluation parameter according to ASTM 311 [68] 317 rather than the recommended substitution amount of the test pozzolan. Therefore, the SAI method is 318 extended to all tested cement paste specimens for all investigated calcination temperatures, substitution 319 degrees and curing ages (Figure 10-12). The examination of the indices reveals that the strength 320 enhancement of specimens at OPC replacement level of $5 \mathrm{wt} \%$ using GWM powders calcined at $850^{\circ} \mathrm{C}$ 321 and $950^{\circ} \mathrm{C}$ was led by the filler effect $[12,13]$. All samples with OPC substitution degrees from 5 wt.\% 322 up to $20 \mathrm{wt} . \%$ fulfilled the minimal SAI requirements according to [61] for all investigated curing ages. 323 At curing age of 7 days (Figure 10), the specimens with a OPC replacement level above 25 wt.\% did not 324 fulfil the minimal requirement, probably related to the dilution effect with increasing pozzolan content 325 which leads to an increased dispersion of cement particles and hence to a lower hydraulic reactivity. 326 Figure 11 and Figure 12 show that, with increasing curing age, most of the specimens with higher OPC 
substitution degrees of 25-30 wt.\% fulfil the minimal level of strength requirement as the pozzolanic

328 reaction becomes more significant with development of additional CSH phases.

329 Figure 13 illustrates the calculated relative strength indices (RSI) of the hardened cement pastes after 56

330 days of curing age. The evaluation of the relative strength indices verify the previous analysis of the

331 strength activity indices by showing a positive relative strength gain after 56 days of curing for the

332 hardened cement pastes using higher OPC substitution degrees of 20-30 wt.\% for all investigated 333 calcination temperatures. The negative values for cement pastes using GWM powders calcined at $750^{\circ} \mathrm{C}$ 334 at a replacement level from 5 to $15 \mathrm{wt} . \%$, respectively, at $950^{\circ} \mathrm{C}$ at a replacement level of $10 \mathrm{wt} . \%$ 335 indicate a relative strength loss by taking into account the substitution degree and the performance of the 336 reference samples. This relative strength loss expresses that at lower substitution degrees, the 337 contribution from pozzolanic reaction to the (relative) strength gain of the cement pastes is lower than 338 the strength development by cement hydration of the reference sample. The highest potential of relative 339 strength gain is reached by the cement pastes containing GWM powders calcined at $850^{\circ} \mathrm{C}$ [69] at an 340 optimal OPC replacement level of $20 \mathrm{wt} . \%$.

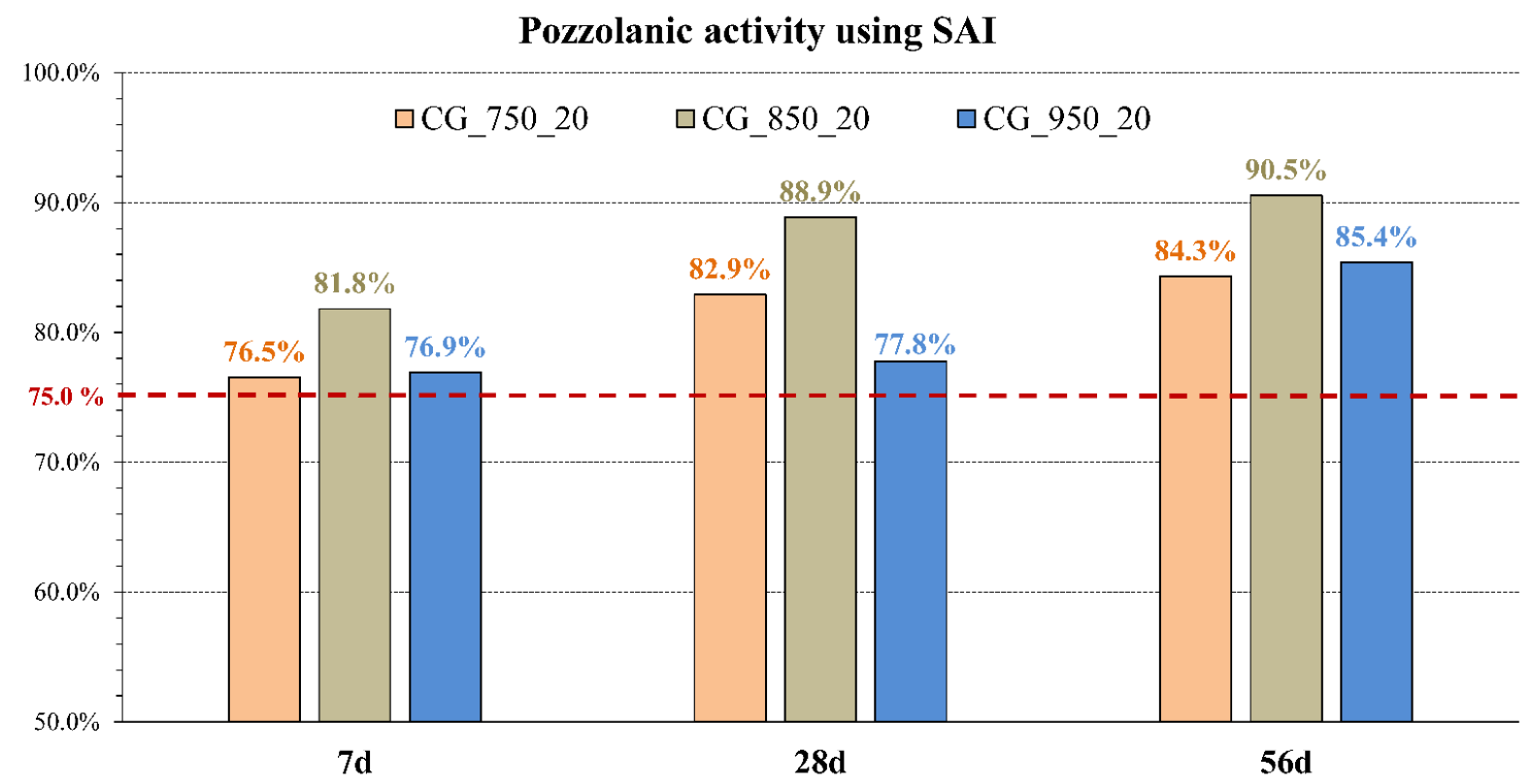

342 Figure 9: Strength activity indices of hardened cement pastes at OPC replacement level of 20 wt.\% containing GWM powders calcined at $750^{\circ} \mathrm{C}, 850^{\circ} \mathrm{C}$ and $950^{\circ} \mathrm{C}$; dashed line represents the limit for 
Pozzolanic activity using SAI- 7 days

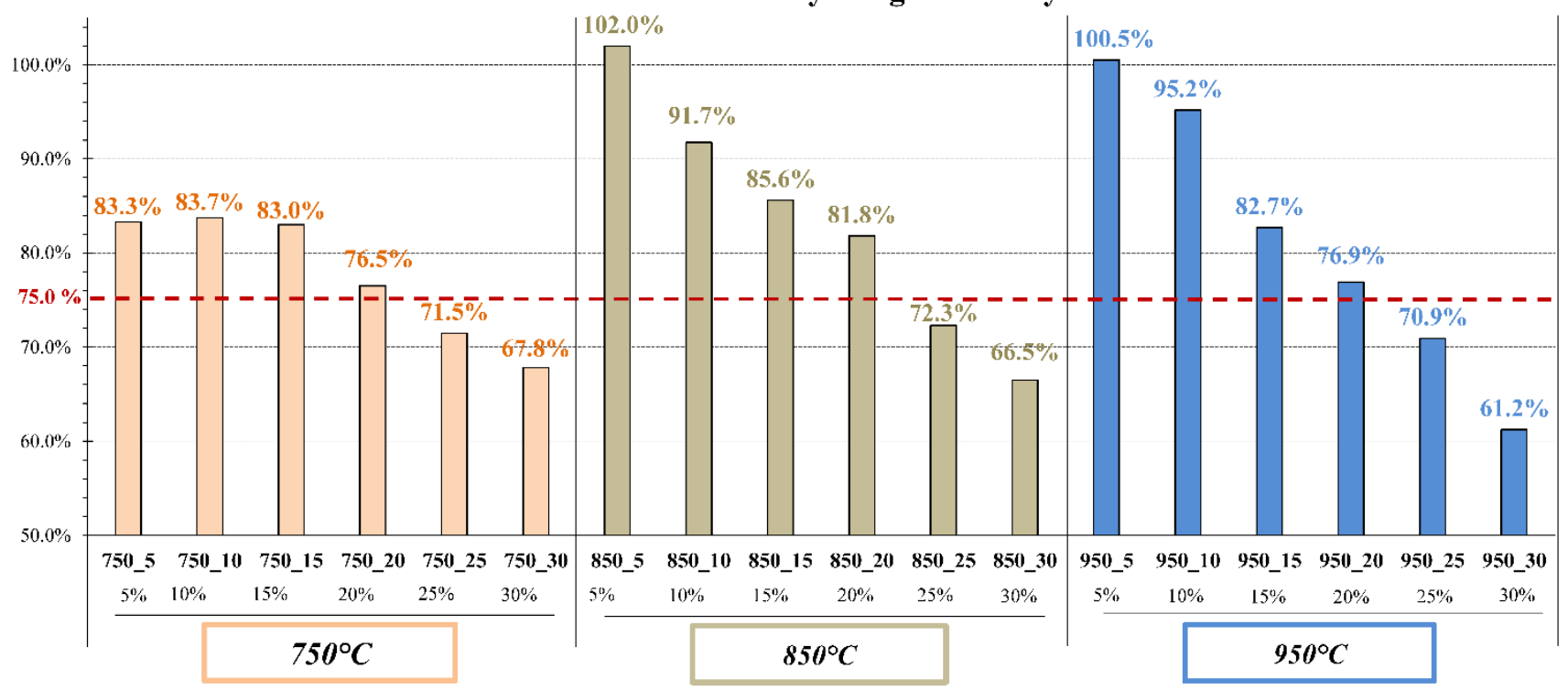

Figure 10: Strength activity indices of hardened cement pastes samples at 7 days of curing age

Pozzolanic activity using SAI- 28 days

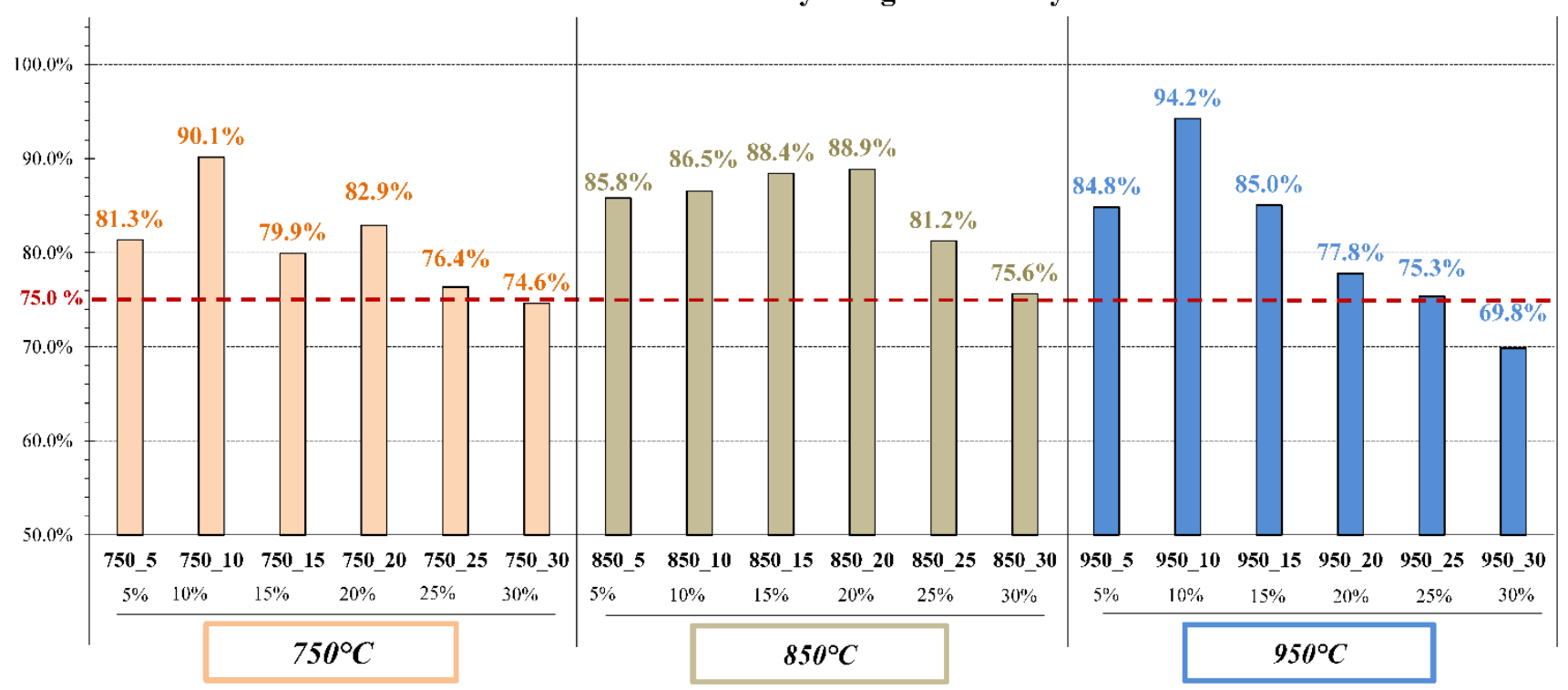

Figure 11: Strength activity indices of hardened cement pastes samples at 28 days of curing age 


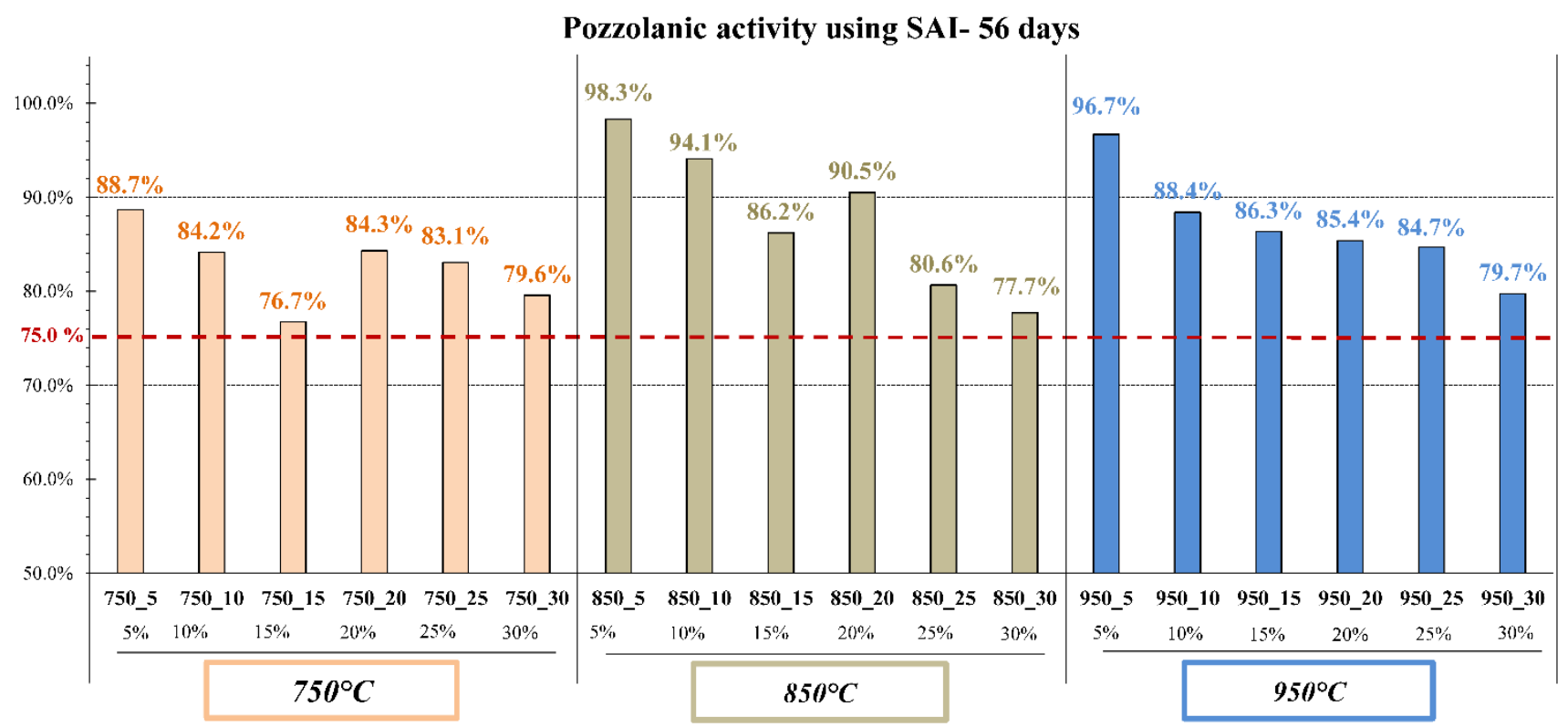

Figure 12: Strength activity indices of hardened cement pastes samples at 56 days of curing age

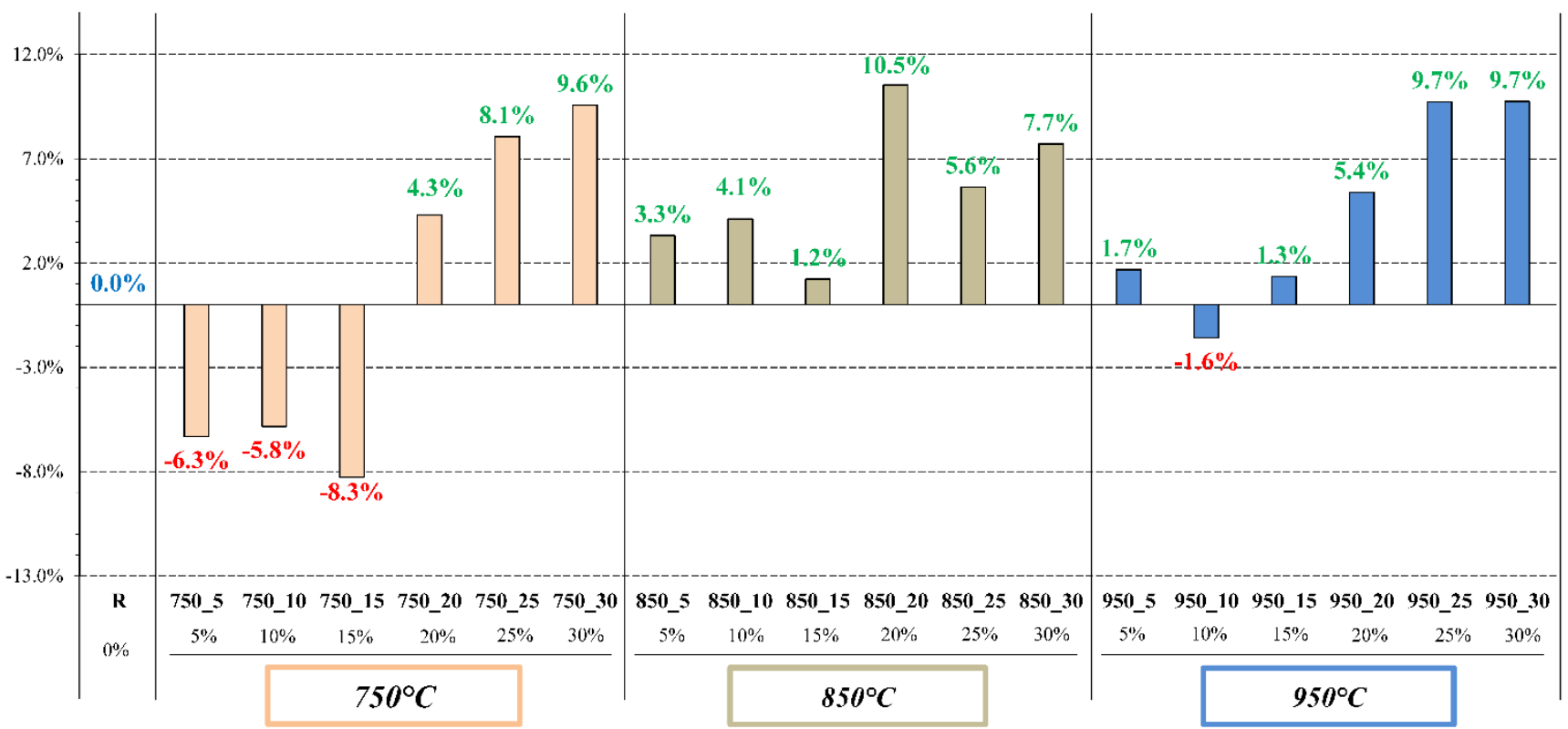

Figure 13: Evaluation of the mechanical performances (curing age of 56 days) of hardened cement pastes samples using the Relative Strength Index (RSI) method

\subsubsection{Phase composition of the hardened specimens by STA}

Figure 14 shows the results of STA of CG_850_20. The TGA curve (green) shows a total mass reduction of $21.83 \%$, which can be divided in three stages: The first mass loss of $9.63 \%$ from room temperature up to $250^{\circ} \mathrm{C}$ occurs due to the heating of the clay minerals, leading to the evaporation of capillary pore water, interlayer water and absorbed water of the CSH phases in the system. The second mass loss of $4.66 \%$ is related to the dehydration of calcium hydroxide (Portlandite). The third loss in 
361 mass of $7.54 \%$ from around $600^{\circ} \mathrm{C}$ up to $750^{\circ} \mathrm{C}$ can be attributed to the decarbonation of calcium

362 carbonate $\left(\mathrm{CaCO}_{3}\right)$ in the binder system. Furthermore, the $\mathrm{CaCO}_{3}$ carbonate results from the carbonation 363 reaction of free Portlandite with $\mathrm{CO}_{2}$ from air as no calcium carbonate was added in the initial mixture.

364 The DSC curve approves the findings of the TG analysis and presents three ranges with endothermic 365 peaks. The first peaks around $100^{\circ} \mathrm{C}$ and $150^{\circ} \mathrm{C}$ represents the dehydration process of the different 366 hydration products and aluminosilicate minerals due to the evaporation of capillary pore water. The 367 second endothermic peak around $450^{\circ} \mathrm{C}$ can be attributed to the dehydration of Portlandite. The final 368 endothermic peaks observed between $700^{\circ} \mathrm{C}$ and $750{ }^{\circ} \mathrm{C}$ correspond to the decarbonation of $\mathrm{CaCO}_{3}$ $369[65,66]$.

\section{TG $/ \%$}

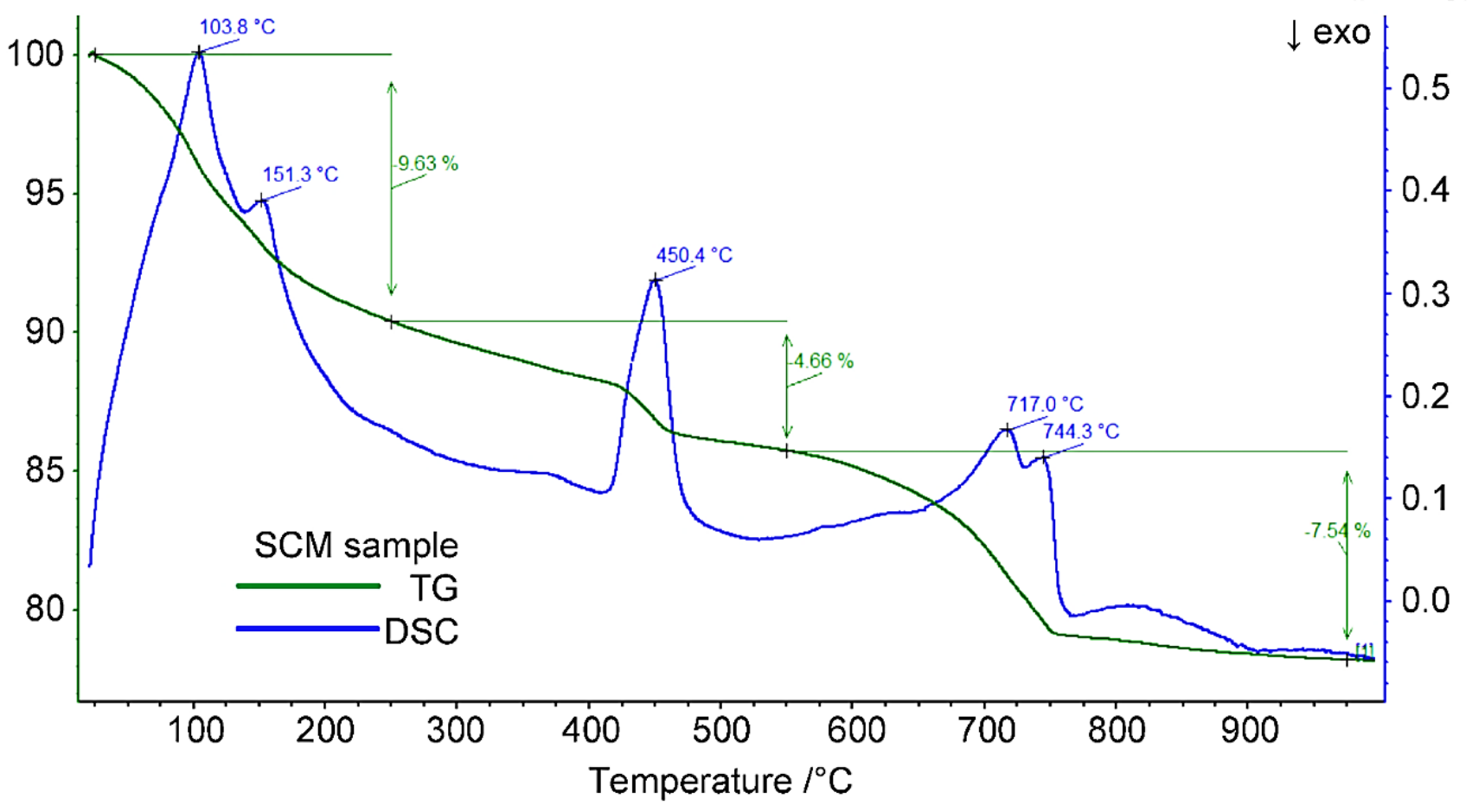

Figure 14: STA (TG-DSC) analysis of CG_850_20

\subsubsection{Analysis of the microstructure}

Figure 15a-c illustrates the images of the microstructure of hardened specimens after 56 days, which were captured by performing SEM on small fractions of the compressed specimens with different replacement levels of CGWM. Figure 15a depicts the SEM image of the control sample and the formation of a compact microstructure of calcium silicate hydrates with Portlandite crystals can be 
377 observed with signs of local failures due to cracking of the hardened paste after the compression test.

378 Figure 15b illustrates the microstructure of a hardened mixed paste with 20 wt. $\%$ of GWM powder 379 calcined at $850^{\circ} \mathrm{C}$. The bond between the hydrate phases and the amorphous cementitious formations 380 results in a compact and dense microstructure. Some irregular cracks were also observed due to the 381 fractioning of the samples. Despite the presence of local aluminosilicate agglomerates, consisting of 382 unmixed/semi-mixed compounds, the hardened mix paste of specimens with low PC replacement level 383 is homogenous and less porous than for specimens with higher substitution degrees due to a better 384 packing of its constituents (filler effect) and a higher degree of cement hydration (Figure 15c). The 385 microstructural analysis of the different samples verify that a compact microstructural composition 386 between the aluminosilicate-rich compounds and the cement-based products was established. This bond 387 suggests the development of pozzolanic reactions between the calcined GWM powders and OPC. 

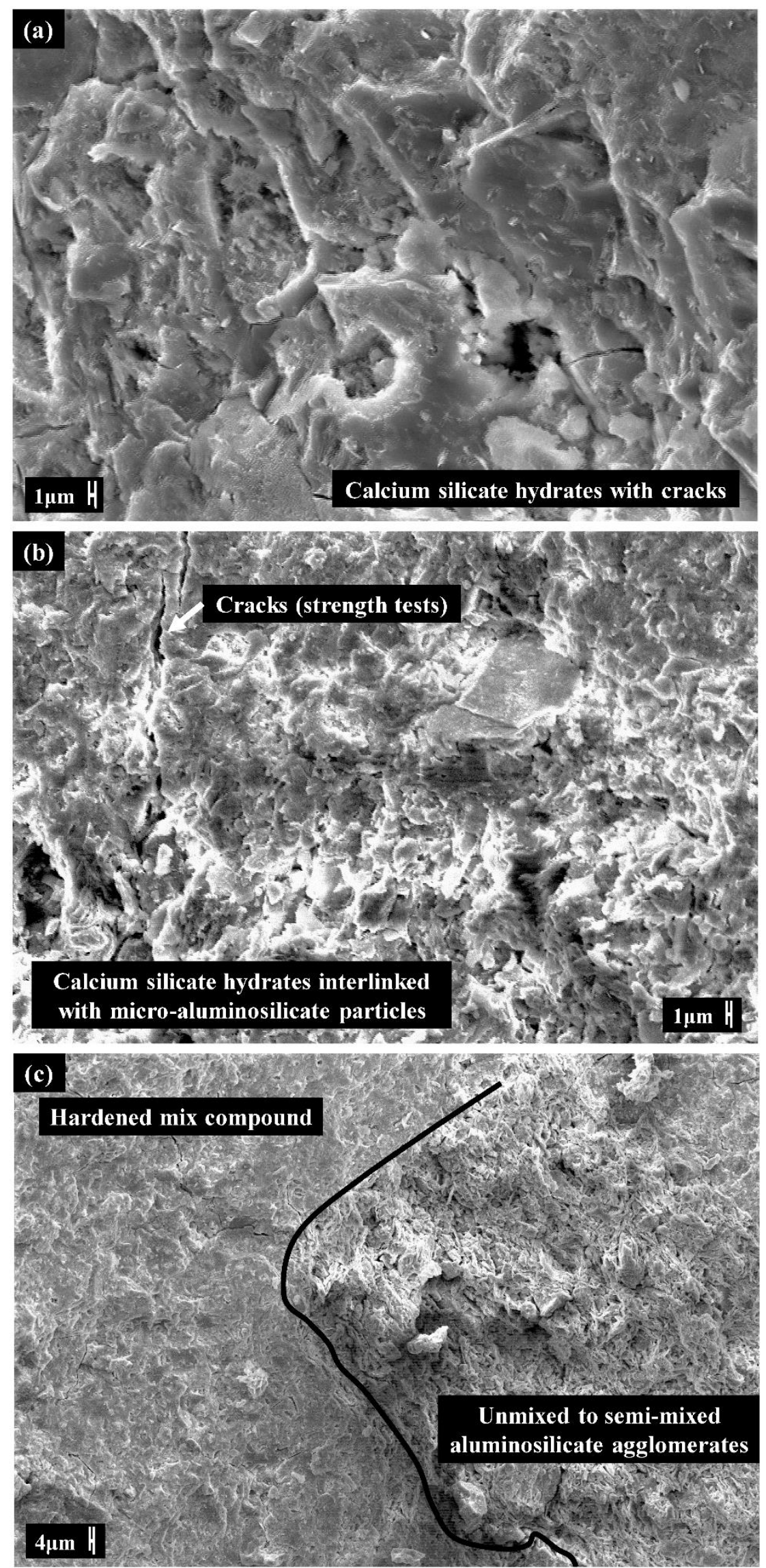

Figure 15: SEM images after 56 days of age: (a) reference mixture CG_R; (b) hardened mixtures CG_850_20; and (c) CG_850_5 


\section{Conclusions}

392 In the present study, gravel wash mud (GWM) powder, an aluminosilicate prime material, derived from 393 a waste sludge from gravel quarrying and after undergoing a calcination process, was evaluated as a 394 novel supplementary cementitious material. From the findings of the different investigations, the 395 following conclusions can be drawn:

396 - The studied GWM powders are fine aluminosilicate-rich materials with a mean particle size 397 around 7-9 $\mu \mathrm{m}$ depending on the applied calcination temperature. The mineralogy is mainly 398 composed of quartz, illite and kaolinite as clay minerals, muscovite, hematite and a high amorphous portion.

- The evaluation of the mineralogy in combination with the STA analysis indicates that the increase of the calcination temperature led to the transfer of the clay phases into reactive hydrous and amorphous phases and therefore suggests the optimum calcination temperature for the GWM powders to be ranged above $750^{\circ} \mathrm{C}$.

- The mechanical strength-based evaluation methods, the SAI and RSI methods applied on all investigated specimens, confirmed the pozzolanic activity of the CGWM powders.

- OPC substitution degrees ranging from $5 \%$ up to $25 \%$ by calcined GWM powders led to the development of a reliable, well-performing hardened cement paste/mortar products.

- The highest compressive strengths were achieved for specimens CG_850_5, CG_950_5 and CG_850_10 with 53.97MPa, 53.07 MPa and 51.66 MPa, respectively. However, the highest strength-enhancing potential regarding the mixing proportions and relative strength gain was observed for the samples containing GWM powders calcined at $850^{\circ} \mathrm{C}$ for one hour with a OPC replacement level of $20 \mathrm{wt} . \%$. A pozzolanic composite cement of CEM II/A-Q or CEM II/B-Q, standardized according to EN 197-1 [47] could be a medium-term option for the use of the calcined GWM powders.

- The associated environmental and economic benefits favour the use of CGWM powders as OPC substitution: The $\mathrm{CO}_{2}$ emissions related to the calcination process of $\mathrm{GWM}$ powder $\left(850^{\circ} \mathrm{C}\right)$ is 
lower than for the sintering $\left(1450^{\circ} \mathrm{C}\right)$ of the prime materials during the production of Ordinary Portland cement. In addition, the waste material is no longer uneconomically landfilled due to its revalorisation as a partial OPC substitute. Nonetheless, further optimization are required, namely on the on-site removal of excess water of wet GWM to avoid extra transport costs if a practicable industrial usage of GWM is intended. From an environmental point of view, if compared directly with the range of different raw materials used to produce cement clinker, the environmental benefit of using GWM or similar industrial waste materials is evident considering the usage of a waste product and consequently the reduced depletion of limited natural resources required for cement clinker production.

426 This study confirms the pozzolanic activity of calcined GWM material as well as its strength-enhancing 427 properties as filler material leading to higher compressive strengths for cementitious mixtures already at 428 lower OPC substitution degrees. Even though promising results were obtained, further research on large429 scale raw material processing, optimization of the mixing proportions, the study of the rheology, 430 durability and other properties of fresh and hardened concrete mixture containing calcined GWM 431 powders as alternative SCM, need to be carried out to implement a sustainable concrete product with a 432 low carbon footprint for constructive applications.

\section{Acknowledgements}

434 The authors would like to express their gratitude to Carrières Feidt S.A. to have kindly supplied the gravel 435 wash mud (GWM) used in this work and Cimalux S.A. with its partner institution Wilhelm Dyckerhoff 436 Institut (WDI), particularly to Dr. Marcus Paul, for their expertise and helpful contributions to the 437 material characterisation. 
439 [1] J. Ke, M. Mcneil, L. Price, N.Z. Khanna, N. Zhou, Estimation of CO2 emissions from China's cement 440 production: Methodologies and uncertainties, 57 (2013) 172-181. doi:10.1016/j.enpol.2013.01.028.

441 [2] E. Benhelal, G. Zahedi, E. Shamsaei, A. Bahadori, Global strategies and potentials to curb CO2 442 emissions in cement industry, J. Clean. Prod. 51 (2013) 142-161. doi:10.1016/j.jclepro.2012.10.049.

443 [3] W. Shen, L. Cao, Q. Li, W. Zhang, G. Wang, Quantifying CO2 emissions from China's cement industry, 444 Renew. Sustain. Energy Rev. 50 (2015) 1004-1012. doi:10.1016/j.rser.2015.05.031.

445 [4] N. Li, D. Ma, W. Chen, Projection of cement demand and analysis of the impacts of carbon tax on cement industry in China, Energy Procedia. 75 (2015) 1766-1771. doi:10.1016/j.egypro.2015.07.457.

447 [5] Y. Cancio, U. Heierli, A.R. Favier, R.S. Machado, K.L. Scrivener, J. Fernando, M. Hernández, G. Habert, $448 \quad$ Limestone calcined clay cement as a low-carbon solution to meet expanding cement demand in emerging economies, 2 (2017) 82-91. doi:10.1016/j.deveng.2017.06.001.

450 [6] K. Scrivener, F. Martirena, S. Bishnoi, S. Maity, Calcined clay limestone cements (LC3), Cem. Concr. Res. 114 (2017) 49-56. doi:10.1016/j.cemconres.2017.08.017.

452 [7] F. Avet, K. Scrivener, Investigation of the calcined kaolinite content on the hydration of Limestone Calcined Clay Cement (LC3), Cem. Concr. Res. 107 (2018) 124-135. doi:10.1016/j.cemconres.2018.02.016.

[8] K.L. Scrivener, V.M. John, E.M. Gartner, Eco-efficient cements: Potential economically viable solutions for a low-CO2cement-based materials industry, Cem. Concr. Res. 114 (2018) 2-26. doi:10.1016/j.cemconres.2018.03.015.

[9] Portland Cement Association, Types and Causes of Concrete Deterioration, PCA R\&D Spec. N. 2617. (2002) 1-16.

[10] Y. Farnam, B. Zhang, J. Weiss, Evaluating the use of supplementary cementitious materials to mitigate damage in cementitious materials exposed to calcium chloride deicing salt, Cem. Concr. Compos. 81 (2017) 77-86. doi:10.1016/j.cemconcomp.2017.05.003.

[11] A. Goldman, A. Bentur, The influence of microfillers on enhancement of concrete strength, Cem. Concr. Res. 23 (1993) 962-972.

[12] G.C. Isaia, A.L.G. Gastaldini, R. Moraes, Physical and pozzolanic action of mineral additions on the 
mechanical strength of high-performance concrete, Cem. Concr. Compos. 25 (2003) 69-76. doi:10.1016/S0958-9465(01)00057-9.

[13] H. Moosberg-Bustnes, B. Lagerblad, E. Forssberg, The function of fillers in concrete, Mater. Struct. Constr. 37 (2004) 74-81. doi:10.1617/13694.

[14] H. Yanguatin, J. Tobón, J. Ramírez, Pozzolanic reactivity of kaolin clays , a review, 32 (2017) 13-24.

[15] V.M. Malhotra, P.K. Metha, Pozzolanic and Cementitious Materials, CRC Press - Taylor \& Francis Group, 2017.

[16] A. Tironi, M.A. Trezza, A.N. Scian, E.F. Irassar, Assessment of pozzolanic activity of different calcined clays, Cem. Concr. Compos. 37 (2013) 319-327. doi:10.1016/j.cemconcomp.2013.01.002.

[17] S. Hollanders, R. Adriaens, J. Skibsted, Ö. Cizer, J. Elsen, Pozzolanic reactivity of pure calcined clays, Appl. Clay Sci. 132-133 (2016) 552-560. doi:10.1016/j.clay.2016.08.003.

[19] F. Avet, X. Li, K. Scrivener, Determination of the amount of reacted metakaolin in calcined clay blends,

[18] M.C.G. Juenger, R. Siddique, Recent advances in understanding the role of supplementary cementitious materials in concrete, Cem. Concr. Res. cli (2015) 71-80. doi:10.1016/j.cemconres.2015.03.018. Cem. Concr. Res. 106 (2018) 40-48. doi:10.1016/j.cemconres.2018.01.009.

[20] S. Seraj, R. Cano, R.D. Ferron, M.C.G. Juenger, The role of particle size on the performance of pumice as a supplementary cementitious material, Cem. Concr. Compos. 80 (2017) 135-142. doi:10.1016/j.cemconcomp.2017.03.009.

[21] E. John, T. Matschei, D. Stephan, Cement and Concrete Research Nucleation seeding with calcium silicate hydrate - A review, Cem. Concr. Res. 113 (2018) 74-85. doi:10.1016/j.cemconres.2018.07.003.

[22] T. Oey, A. Kumar, J.W. Bullard, N. Neithalath, G. Sant, The Filler Effect: The Influence of Filler Content and Surface Area on Cementitious Reaction Rates, 14th Int. Congr. Chem. Cem. (2015) 1-33.

[23] G.C. Cordeiro, R.D. Toledo Filho, L.M. Tavares, E.M.R. Fairbairn, Pozzolanic activity and filler effect of sugar cane bagasse ash in Portland cement and lime mortars, Cem. Concr. Compos. 30 (2008) 410-418. doi:10.1016/j.cemconcomp.2008.01.001.

[24] J. Tangpagasit, R. Cheerarot, C. Jaturapitakkul, K. Kiattikomol, Packing effect and pozzolanic reaction of fly ash in mortar, Cem. Concr. Res. 35 (2005) 1145-1151. doi:10.1016/j.cemconres.2004.09.030.

[25] I. Mehdipour, A. Kumar, K.H. Khayat, Rheology, hydration, and strength evolution of interground 
limestone cement containing PCE dispersant and high volume supplementary cementitious materials,

[26] K. De Weerdt, M. Ben Haha, G. Le Saout, K.O. Kjellsen, H. Justnes, B. Lothenbach, Hydration mechanisms of ternary Portland cements containing limestone powder and fly ash, Cem. Concr. Res. 41

[27] V. Della, I. Kuhn, D. Hotza, Rice husk ash as an elemente source for active silicaproduction, Mater. Lett. 57 (2002) 818-821. doi:10.1016/S0167-577X(02)00879-0.

[28] N. Zemke, E. Woods, Rice Husk Ash, Rice Husk Ash. (2009) 1-12. http://www.cvbtweb.org/uploads/Rice_Husk_Ash/Nick_Emmet_RHA.pdf.

[29] M.F.M. Zain, M.N. Islam, F. Mahmud, M. Jamil, Production of rice husk ash for use in concrete as a supplementary cementitious material, Constr. Build. Mater. 25 (2011) 798-805. doi:10.1016/j.conbuildmat.2010.07.003.

[30] R.S. Almenares, L.M. Vizcaíno, S. Damas, A. Mathieu, A. Alujas, F. Martirena, Industrial calcination of kaolinitic clays to make reactive pozzolans, Case Stud. Constr. Mater. 6 (2017) 225-232. doi:10.1016/j.cscm.2017.03.005.

[31] D. Zhou, R. Wang, M. Tyrer, H. Wong, C. Cheeseman, Sustainable infrastructure development through use of calcined excavated waste clay as a supplementary cementitious material, J. Clean. Prod. 168 (2017) 1180-1192. doi:10.1016/j.jclepro.2017.09.098.

[32] R.D. Toledo Filho, J.P. Gonçalves, B.B. Americano, E.M.R. Fairbairn, Potential for use of crushed waste calcined-clay brick as a supplementary cementitious material in Brazil, Cem. Concr. Res. 37 (2007) 1357-1365. doi:10.1016/j.cemconres.2007.06.005.

[33] L.R. Steiner, A.M. Bernardin, F. Pelisser, Effectiveness of ceramic tile polishing residues as supplementary cementitious materials for cement mortars, Sustain. Mater. Technol. 4 (2015) 30-35. doi:10.1016/j.susmat.2015.05.001.

[34] S. Wild, J.M. Khatib, O. M., Sulphate resistance of mortar, containing ground brick clay calcined at different temperatures, 27 (1997) 697-709.

[35] L.A. Pereira-de-oliveira, J.P. Castro-gomes, P.M.S. Santos, The potential pozzolanic activity of glass and red-clay ceramic waste as cement mortars components, Constr. Build. Mater. 31 (2012) 197-203. doi:10.1016/j.conbuildmat.2011.12.110. 
523 [36] Y. Labbaci, B. Labbaci, Y. Abdelaziz, A. Mekkaoui, A. Alouani, The use of the volcanic powders as supplementary cementitious materials for environmental-friendly durable concrete, Constr. Build. Mater. 133 (2017) 468-481. doi:10.1016/j.conbuildmat.2016.12.088.

[37] A. Ababneh, F. Matalkah, Potential use of Jordanian volcanic tuffs as supplementary cementitious materials, Case Stud. Constr. Mater. 8 (2018) 193-202. doi:10.1016/j.cscm.2018.02.004.

[38] W.Y. Kuo, J.S. Huang, T.E. Tan, Organo-modified reservoir sludge as fine aggregates in cement mortars, Constr. Build. Mater. 21 (2007) 609-615. doi:10.1016/j.conbuildmat.2005.12.009.

[39] O. Rodríguez, L. Kacimi, A. López-delgado, M. Frías, A. Guerrero, Characterization of Algerian reservoir sludges for use as active additions in cement : New pozzolans for eco-cement manufacture, 40 (2013) 275-279. doi:10.1016/j.conbuildmat.2012.10.016.

[40] V.B. Thapa, D. Waldmann, J.-F. Wagner, A. Lecomte, Assessment of the suitability of gravel wash mud

[41] Ł. Kotwica, W. Pichór, E. Kapeluszna, A. Różycka, Utilization of waste expanded perlite as new

[42] E. Aprianti S, A huge number of artificial waste material can be supplementary cementitious material

[44] J.M. Paris, J.G. Roessler, C.C. Ferraro, H.D. Deford, T.G. Townsend, A review of waste products utilized doi:10.1016/j.jclepro.2015.12.115.

[43] E. Aprianti, P. Shafigh, S. Bahri, J.N. Farahani, Supplementary cementitious materials origin from agricultural wastes - A review, Constr. Build. Mater. 74 (2015) 176-187. doi:10.1016/j.conbuildmat.2014.10.010. as supplements to Portland cement in concrete, J. Clean. Prod. 121 (2016) 1-18. doi:10.1016/j.jclepro.2016.02.013.

[45] G. Quercia, J.J.G. Van Der Putten, G. Hüsken, H.J.H. Brouwers, Photovoltaic's silica-rich waste sludge as supplementary cementitious material (SCM), Cem. Concr. Res. 54 (2013) 161-179. doi:10.1016/j.cemconres.2013.08.010. 
551 [46] P.F.G. Banfill, Alternative materials for concrete- Mersey silt as fine aggregate, Build. Environ. 15 (1980) 181-190. doi:10.1016/0360-1323(80)90035-9.

[47] DIN EN 197-1:2011-11, Cement - Part 1: Composition, specifications and conformity criteria for common cements, European Committee for standardization, 2011.

[48] DIN EN 196-1:2016-11, Methods of Testing Cement - Part 1: Determination of Strength, European Committee for standardization, 2016.

[49] R.W. Cheary, A.A. Coelho, J.P. Cline, Fundamental parameters line profile fitting in laboratory

[50] H.M. Rietveld, A profile refinement method for nuclear and magnetic structures, J. Appl. Crystallogr. 2 (1969) 65-71. doi:10.1107/S0021889869006558.

[51] A.H. De Aza, A.G. De La Torre, M.A.G. Aranda, F.J. Valle, S. De Aza, Rietveld Quantitative Analysis

[53] Y. Liu, S. Lei, M. Lin, Y. Li, Z. Ye, Y. Fan, Assessment of pozzolanic activity of calcined coal-series kaolin, Appl. Clay Sci. 143 (2017) 159-167. doi:10.1016/j.clay.2017.03.038.

[57] A. Bakolas, E. Aggelakopoulou, A. Moropoulou, Evaluation of pozzolanic activity and physico-

[54] Y. Shao, T. Lefort, S. Moras, D. Rodriguez, Studies on concrete containing ground waste glass, Cem. Concr. Res. 30 (2000) 91-100. doi:10.1016/S0008-8846(99)00213-6.

[55] A. Shvarzman, K. Kovler, G.S. Grader, G.E. Shter, The effect of dehydroxylation / amorphization degree on pozzolanic activity of kaolinite, 33 (2003) 405-416. doi:10.1016/S0008-8846(02)00975-4.

C. Shi, Y. Wu, C. Riefler, H. Wang, Characteristics and pozzolanic reactivity of glass powders, Cem. Concr. Res. 35 (2005) 987-993. doi:10.1016/j.cemconres.2004.05.015. mechanical characteristics in ceramic powder-lime pastes, J. Therm. Anal. Calorim. 84 (2006) 157-163. doi:10.1007/s10973-007-8858-1.

[58] S. Donatello, M. Tyrer, C.R. Cheeseman, Comparison of test methods to assess pozzolanic activity, Cem. Concr. Compos. 32 (2010) 121-127. doi:10.1016/j.cemconcomp.2009.10.008.

D.P. Bentz, A. Durán-Herrera, D. Galvez-Moreno, Comparison of ASTM C311 Strength Activity Index Testing versus Testing Based on Constant Volumetric Proportions, J. ASTM Int. 9 (2012) 104138. 
581 [60] A. Tironi, M.A. Trezza, A.N. Scian, E.F. Irassar, Kaolinitic calcined clays: Factors affecting its performance as pozzolans, Constr. Build. Mater. 28 (2012) 276-281. doi:10.1016/j.conbuildmat.2011.08.064.

[61] A. Tironi, F. Cravero, A.N. Scian, E.F. Irassar, Pozzolanic activity of calcined halloysite-rich kaolinitic clays, Appl. Clay Sci. 147 (2017) 11-18. doi:10.1016/j.clay.2017.07.018.

586 [62] R.L. Coble, Effects of particle-size distribution in initial-stage sintering, J. Am. Ceram. Soc. 56 (1973) $461-466$.

[63] V.-G. Lee, T.-H. Yeh, Sintering effects on the development of mechanical properties of fired clay ceramics, Mater. Sci. Eng. A. 485 (2008) 5-13.

[64] Paul, M. (2018). Quality control of autoclaved aerated concrete by means of X-ray diffraction. ce/papers, 2(4), 111-116. doi.org/10.1002/cepa.894.

592 [65] B. Wunderlich, Thermal analysis of polymeric materials, Springer Science \& Business Media, 2005. doi:10.1520/C0618-12A.

594 [66] R.C. Mielenz, N.C. Schieltz, M.E. King, Thermogravimetric analysis of clay and clay-like minerals, Clay Clay Miner. (1953) 285-314.

[67] ASTM C618-12a, Standard Specification for Coal Fly Ash and Raw or Calcined Natural Pozzolan for Use in Concrete, ASTM International.

[69] S. Ferreiro, M.M.C. Canut, J. Lund, D. Herfort, Influence of fineness of raw clay and calcination 81-90. doi:10.1016/J.CLAY.2018.12.021. 